\title{
Residir en contexto republicano en Antofagasta de la Sierra, Puna meridional argentina. Un abordaje desde la materialidad textil
}

M. Soledad Martinez*
Recibido:

15 de marzo de 2019

Aceptado:

12 de diciembre de 2019

\section{Resumen}

Desde la materialidad textil buscamos dar cuenta y definir espacios de negociación en contextos de transformación social, política y económica. Partimos del análisis de un conjunto textil histórico recuperado en una de las estructuras de falsa bóveda que conforma el sitio Peñas Coloradas 3 cumbre. El sitio se ubica en la cumbre de una peña en el curso medio-inferior del río Las Pitas, Antofagasta de la Sierra, Catamarca. Las diferentes estructuras arquitectónicas han sido asignadas al período Tardío-Inca (900-1490 d.C.), algunas de las cuales han sido reutilizadas en contexto republicano (1800-1900 d.C.). Los fechados radiocarbónicos, las características tecno-productivas y los contextos de excavación ubican a la evidencia textil en ca.T 1800-1900 d.C. A partir de la caracterización del conjunto textil seleccionado, observamos la combinación de tradiciones tecnológicas diferentes (industrial/artesanal) que confluyen en una misma pieza. Esta particular característica es interpretada como una respuesta de las/los puneñas/os a los cambios sociales y políticos, propios de la organización territorial de los estados modernos. En este sentido, destacamos la persistencia con transformaciones de la materialidad textil, vinculada a las identidades puneñas, en un nuevo contexto sociopolítico.

\section{Dwelling in republican context in Antofagasta de la Sierra, Argentine southern Puna. An approach from textile materiality}

\begin{abstract}
This paper intends to account for and define negotiation spaces in contexts of social, political, and economic transformation, through the study of textile materiality. In this way, we analyzed a historical textile assemblage recovered from one of the false vault structures located at the archaeological site of Peñas Coloradas 3 summit. This site is located on top of a crag in the middle-lower course of Las Pitas' river, Antofagasta de la Sierra, Catamarca. The different architectural structures have been assigned to the Late-Inca period (900-1490 A.D.), but some of them have been reused during the
\end{abstract}

Palabras clave

Textiles históricos Espacios de negociación Persistencia
Keywords

Historical textiles Negotiation spaces Persistence

\footnotetext{
* Instituto de Arqueología y Museo (IAM), Facultad de Ciencias Naturales e Instituto Miguel Lillo, Universidad Nacional de Tucumán (UNT). Instituto Superior de Estudios Sociales (ISES), CONICET. San Martín 1545 (CP T4000CWE), San Miguel de Tucumán, Tucumán, Argentina. E-mail: solemartinez216@hotmail.com
} 
republican context (1800-1900 A.D.). Radiocarbon dating, techno-productive features, and the excavation context date the textile evidence in the last two centuries of the second millennia. From the technological analysis of the textile selected sample we observe the combination of different technological traditions (industrial/artisanal) in the same piece. This particular trait is interpreted as a response of the Puna people to the social and political changes in the context of the territorial organization of modern states. In this sense, the results of our work suggest the persistence of textile materiality related to punean identities, in a new sociopolitical context.

\section{Introducción}

Entre las últimas décadas del siglo XX y los primeros decenios del siglo XXI, las ciencias sociales abordaron el estudio de la construcción de identidad en los colectivos sociales a partir de ejes inclusivos y plurales. Ejemplos de ello han sido los trabajos de Boccara (2002, 2012), Briones (2005), Escolar (2007), Isla (2005), Jones (2005), Voss (2008), entre otros. Las identidades sociales como parte de procesos históricos conllevan permanencias, transformaciones y resignificaciones en los modos de vivir de una sociedad. La arqueología, a partir del estudio del mundo material y como disciplina social, tiene un fuerte impacto en las identidades de los pueblos puneños del noroeste argentino. Las mismas se fueron transformando a lo largo de milenios en un paisaje que se vio afectado por procesos de distinta magnitud y repercusión entre las poblaciones locales. Entre estos procesos enfatizamos particularmente el establecimiento del Estado Nación en el "desierto inhóspito", tal como la literatura del siglo XIX y principios del siglo XX definió a este sector de la Puna meridional (Benedetti, 2002, 2005, 2009).

Es por ello que proponemos que en ciertas prácticas sociales, como las vinculadas al textil, los actores construyeron espacios de negociación, como una de las múltiples respuestas al poder en las estructuras del orden estatal y nacional. Planteamos que a partir de la creatividad, el ingenio y la transformación de las materialidades (Miller, 2005) las poblaciones puneñas establecieron una relación diferente con las nuevas normativas económicas, sociales y políticas. Los sujetos construyeron, y aún construyen, identidades dinámicas que conjugan, combinan y articulan los recursos propios de la modernidad con materialidades preexistentes de carácter ancestral, para enfrentarse a una nueva realidad y generar prácticas locales vinculadas a la cordelería y a la textilería.

Nuestro caso de estudio implica un abordaje teórico metodológico de un conjunto textil, compuesto por telas industriales, tejidos y cordeles artesanales, recuperado en una estructura arquitectónica abovedada en el Sitio Peñas Coloradas 3-cumbre, cuya cronología se extiende desde el 800 cal. d.C. al 1960 cal. d.C. (Cohen, 2014).

En este caso, buscamos identificar las experiencias locales de la población puneña ante el arribo de un nuevo orden social y la implementación de políticas liberales, teniendo en cuenta la "bifocalidad" planteada por Gupta y Ferguson (2008). En este contexto, nos interesa dar cuenta de la persistencia (Silliman, 2009) de la materialidad textil, siendo en la actualidad una de las prácticas de mayor representatividad social y económica en el lugar.

\section{Antofagasta de la Sierra: Escenario socio histórico}

La Puna de Atacama estuvo sujeta a disputas territoriales entre Bolivia, Chile y Argentina durante el siglo XIX. Actualmente el área denominada Antofagasta de la Sierra se encuentra en territorio argentino (Figuras 1 y 2), en el departamento homónimo de la 
provincia de Catamarca. Las características ambientales muestran las condiciones de aridez y la marcada amplitud térmica diurna/nocturna típicas de desierto de altura. El área se encuentra dominada por la cuenca endorreica del río Punilla (entre 3.400 y $4.900 \mathrm{~m}$ s.n.m.), conformada por cursos de agua permanentes y semipermanentes, cuyos caudales alimentan la laguna de Antofagasta, al pie del complejo volcánico Los Negros. En la actualidad, la localidad de Antofagasta de la Sierra cuenta con 1.493 habitantes (Instituto Nacional de Estadística y Censos, 2012) (Figura 3).

Hasta el momento, las evidencias arqueológicas muestran un "registro de continuidad ocupacional - desde 10.000 años AP — vinculado con la explotación de recursos en parches, donde la caza y el pastoreo fueron sucesivamente el eje de subsistencia" (Aschero, 2007, p. 136). El paisaje antofagasteño comprende numerosos lugares de uso persistente, habitados durante milenios por sociedades cazadoras recolectoras y grupos agropastoriles que, al momento de la ocupación Incaica del Noroeste argentino, complejizaron su organización social para luego incorporarse con sus particularidades al orden colonial y al del Estado Nación. Se identificaron espacios con ocupaciones residenciales, áreas de producción, localidades de congregación, sitios rituales o caravaneros, ámbitos de los ancestros y sectores con recursos vegetales animales y minerales (Aschero et al., 2016).

A continuación, dada la evidencia textil recuperada en contextos de excavación (18001900 d.C.), nos referiremos al contexto socio-político correspondiente a los últimos siglos de nuestra era.

\section{Contexto republicano}

Entre fines del siglo XVIII e inicios del siglo XIX los indígenas - y en algunas áreas colonizadas, los esclavos negros - eran la base de muchas de las estructuras productivas coloniales y republicanas. Sin embargo, las políticas liberales de principios del siglo XIX propiciaron y enmascararon, a través de la bandera de progreso, modernidad e igualdad, una homogeneidad y fraternidad de la República que anulaba la diversidad de estas poblaciones (Martínez, Gallardo y Martínez, 2002).

Con la implementación de las políticas liberales se da el pasaje a una economía dominada por el sistema capitalista, con la concepción de propiedad privada y las nuevas relaciones de producción. Las reformas del siglo XIX, luego de la emancipación colonial, incluyeron la abolición del tributo, de la tenencia colectiva de la tierra y del sistema de autoridades étnicas, entre otras. En este contexto, y dado que las elites criollas necesitaban al indígena económicamente, se desarrolla una retórica de igualdad; sin embargo, y contradictoriamente, estos sujetos fueron negados sociopolíticamente.

Con el objetivo de negar el pasado prehispánico y de alcanzar el modelo de sociedad europeo, las acciones del Estado nacional estuvieron orientadas a favorecer la integración material y cultural de los territorios mediante la construcción de infraestructura de circulación y el establecimiento de escuelas y otras instituciones de disciplinamiento social (Benedetti, 2002). En este "disciplinamiento social" - y en un territorio con trayectorias históricas milenarias-, se da una imposición del Estado. Se generan normas, regulaciones, lógicas, categorías y nociones que implican nuevas políticas prácticas (sensu Silliman, 2001) de la población puneña en tiempos republicanos. A partir de lo expuesto surge la siguiente pregunta: ¿cómo se insertan espacios de autonomía en este nuevo contexto y a través de qué prácticas se materializan?

Entendemos al espacio social como construcción relacional que define acercamientos y distancias sociales (Bourdieu, 1990). Postulamos que las sociedades puneñas, 


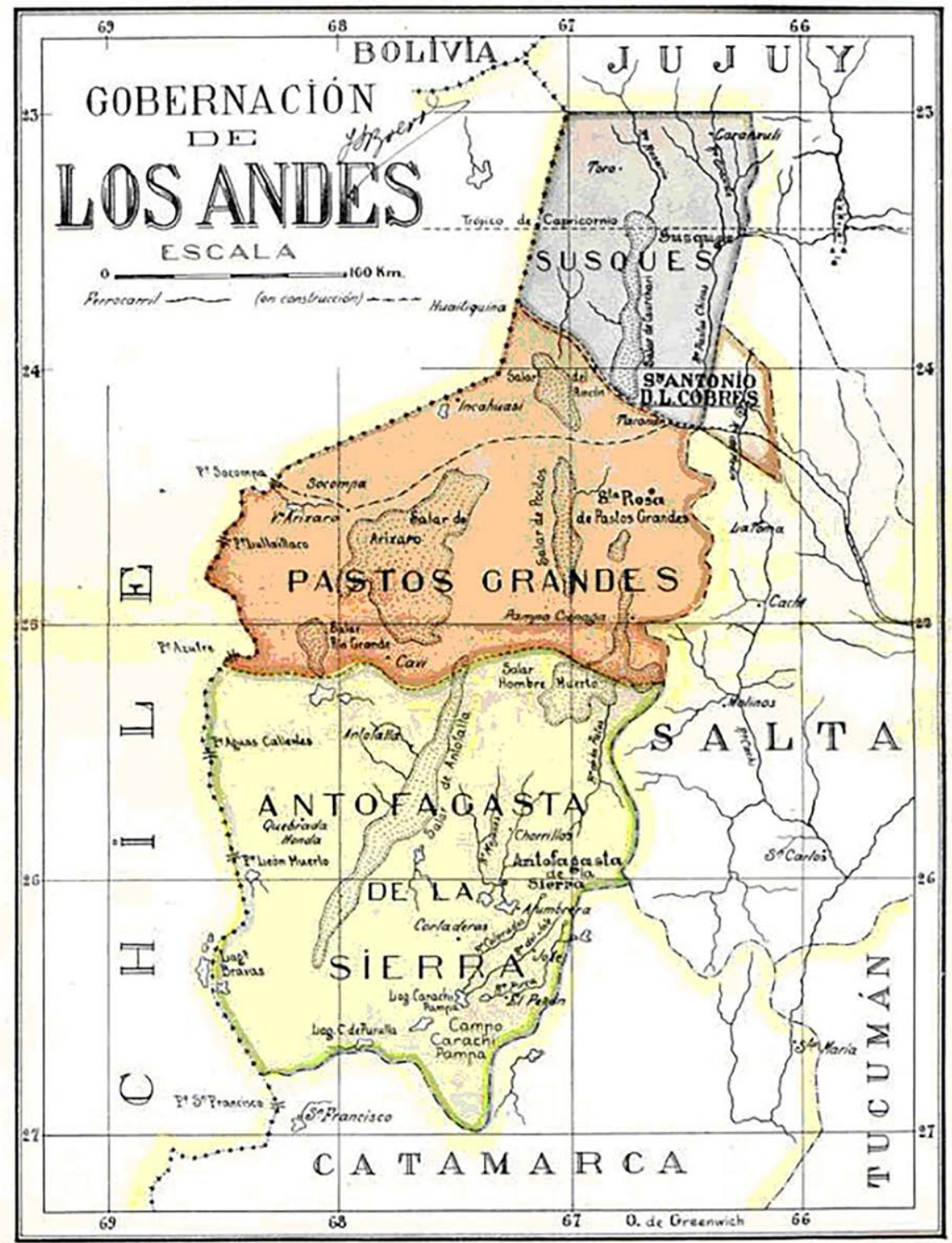

Figura 1. Mapa de la Gobernación de los Andes orientado al Norte, Antofagasta de la Sierra como parte del territorio argentino en el Siglo XX (Boero, 1941 en Benedetti, 2005, p. 266).

con una historia profunda en la cual pudieron superar cambios sociopolíticos de diferente magnitud, respondieron a la nueva realidad social a través de sus prácticas y materialidades con una lógica propia. Proponemos en este trabajo analizar las particularidades en las formas de habitar Antofagasta de la Sierra en contexto republicano, reflexionando sobre la construcción de espacios de negociación reflejados en la materialidad textil como parte de la identidad puneña, en el marco de procesos globales de dominio político, económico y social.

\section{Tierra de textiles, textiles en la tierra}

Con base en numerosas investigaciones en diversas disciplinas sociales, se ha podido comprobar que en las comunidades andinas, las prácticas sociales relacionadas al 


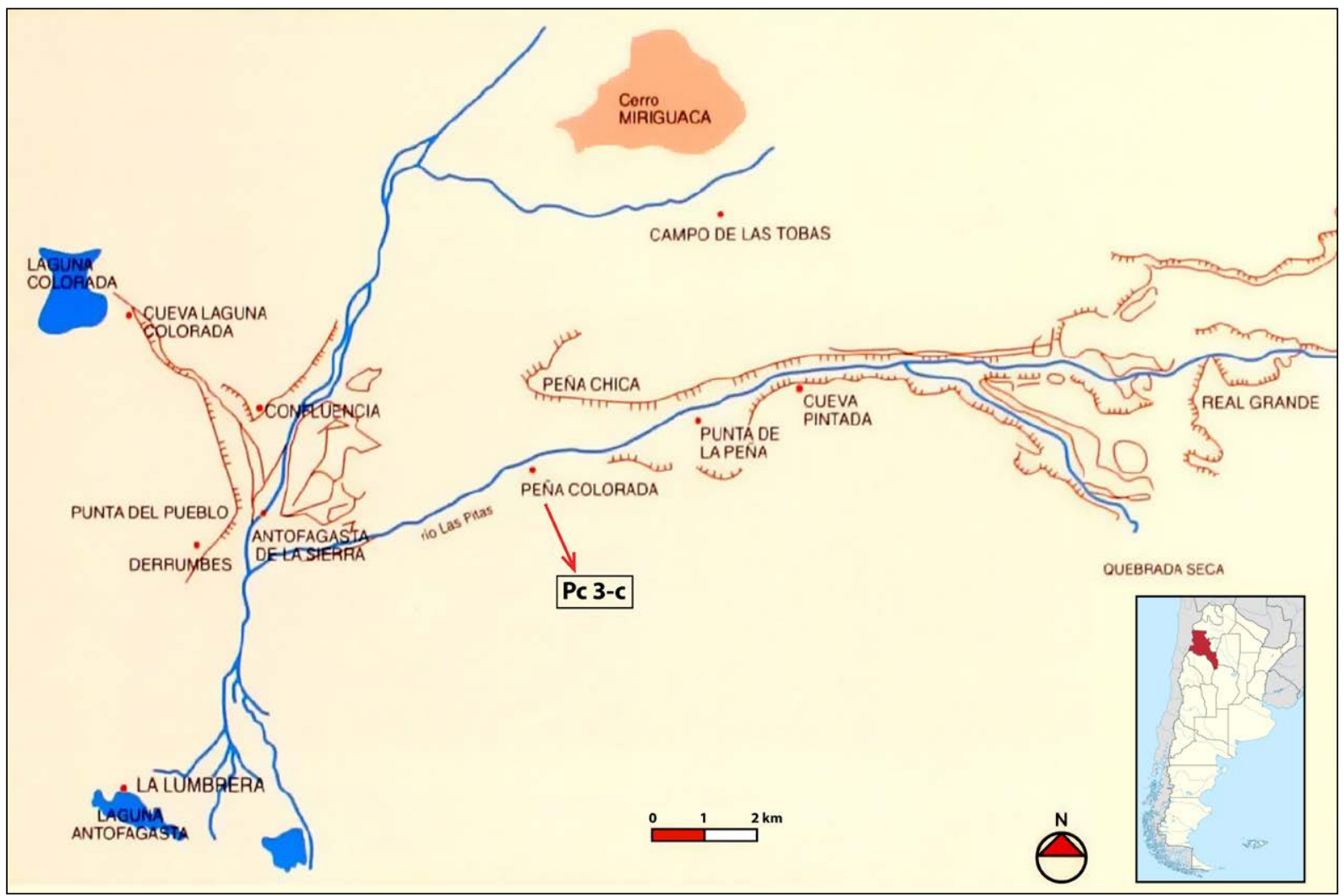

Figura 2. Mapa de la microrregión de Antofagasta de la Sierra, provincia de Catamarca y ubicación de Peñas Coloradas 3-cumbre. Modificado de Aschero (1999).

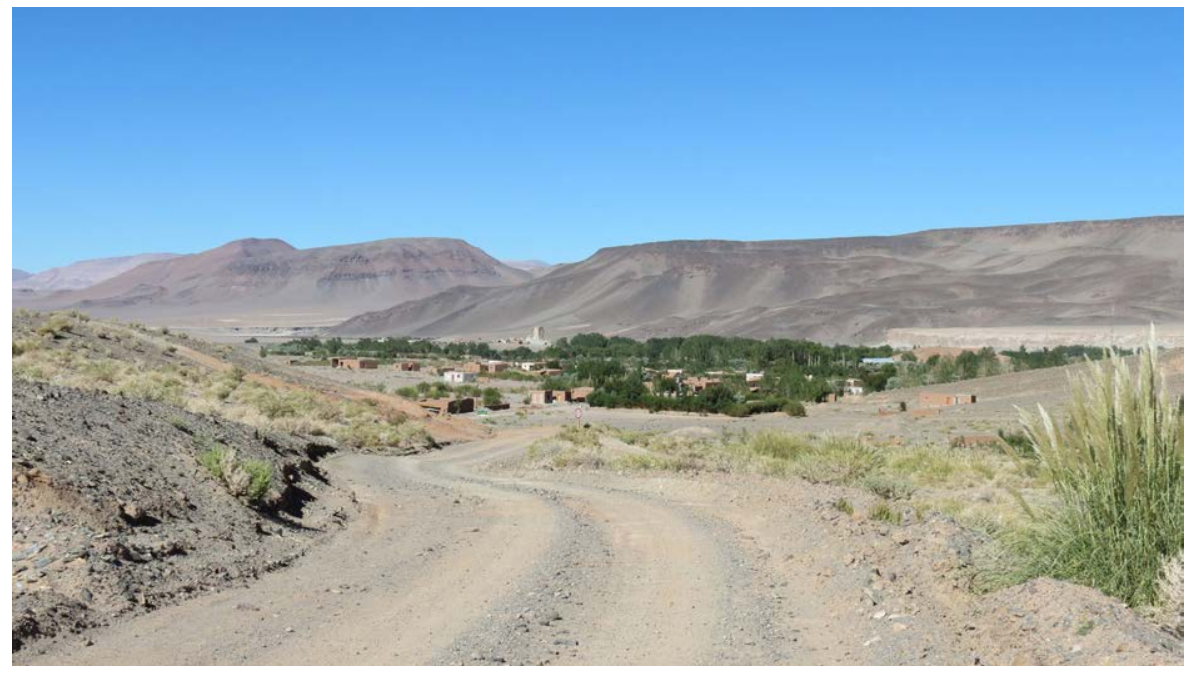

Figura 3. Antofagasta de la Sierra. Localidad de la provincia de Catamarca, Noroeste de Argentina.

universo textil y, particularmente, sus productos, han sido considerados de diversas maneras. Se han entendido como bienes de prestigio, soportes materiales y visuales de identidades sociales y como parte de la memoria social, es decir, como portadores de mensajes y/o significados específicos (Aláez García, 2001; Arnold, 1998, 2000; Cereceda, 1990; Corcuera, 2006; Gisbert, Arze y Cajías, 1987; López Campeny, 2001, 2006-2007; Martinez, 2013; Murra, 1975; Van Kessel, 2001; entre otros). A su vez, las prácticas sociales vinculadas al mundo andino y al paisaje puneño donde textiles $y$ 
cordeles cobran relevancia, han sido muy bien documentadas en diferentes trabajos de investigación (Flores Ochoa y Kobayashi, 2000; García y Rolandi, 2000, 2003; Iñiguez y Alem, 1996; Lecoq y Fidel, 2003; López Campeny, 2006-2007, 2014; Martinez, 2012, 2013; Rolandi de Perrot y Jiménez de Pupareli, 1983-1985).

En Antofagasta de la Sierra la práctica vinculada a la textilería y cordelería se remonta, según las investigaciones arqueológicas actuales, a momentos en que las sociedades cazadoras- recolectoras habitaban este sector de la Puna argentina (Martínez, Mondini, Pintar y Reigadas, 2010; Martinez, 2014). Los productos textiles más tempranos proceden de contextos funerarios con una cronología de $8440 \pm 40$ años AP. Se trata de la estructura funeraria (FS1) de Peñas de las Trampas 1.1, donde se depositó un conjunto de mallas confeccionadas por enlace y torsión de hilados de fibra vegetal Acrocomia chunta (Martinez, 2014). Otros hallazgos de cordelería elaborada con Acrocomia se presentan dentro de una extensa secuencia ocupacional: ca. 7000 años AP - sitio Quebrada Seca 3-, ca. 3600 años AP - sitio Punta de la Peña 11- y ca. 1400 años AP -sitio Punta de la Peña 9 Estructura III- (López Campeny, 2000; López Campeny, Romano, Rodriguez, Martel y Corbalán, 2014; Rodríguez, 2005, 2008). En dos casos se trata de contextos funerarios. Es significativo destacar que el conjunto de prendas procedente de Punta de la Peña 9, confeccionadas en fibra de llama, exhibe un despliegue de técnicas en faz de urdimbre y tapicería, evidencia de teñido y una elevada destreza en el procesamiento de las fibras hiladas que nos habla de gran experiencia en el manejo de las fibras textiles, y de prácticas con raíces muy profundas en el tiempo (López Campeny, 2001, 2002, 2006-2007). A su vez, se tiene un fuerte soporte empírico de la participación de textiles y cordeles en distintos contextos rituales vinculados a sociedades agropastoriles (Babot et al., 2006; López Campeny, 2009; Urquiza, Romano y López Campeny, 2013). Para el período Tardío Inka se cuenta con las piezas procedentes del alero Punta de la Peña 4. Éstas constituyen un conjunto integrado por un elemento de cordelería que cumplía con las funciones de "amarre" de un fardo funerario, un unku o túnica andina y dos bolsas o contenedores identificados como costales (López Campeny, 2009, 2014; López Campeny y Aschero, 2006).

En cuanto a la circulación y utilización de textiles a fines del siglo XVIII y principios del siglo XIX, Palomeque (1989) señala que en Catamarca, entre 1799 y 1810, las exportaciones de textiles sobrepasan notablemente al consumo de lienzos o tejidos importados y su estabilidad depende principalmente de la continuidad del tejido doméstico artesanal para las telas de algodón.

(...) El sexo femenino es bastante industrioso y aplicado a fabricar lienzo de todas calidades, especialmente el ordinario que surte a las tres provincias, de suerte que no ay casa ni rancho en todo su distrito que no tenga uno o dos telares, con su torno para hilar y otro para desmotar algodón. También se aplican a bordar paños de mano finos como también bayetillas de algodón que exceden en la duración a las de España; hasta que se lavan porque las tintas no agarran bien en el algodón; hasta los clérigos se visten de estos bayetones negros y los seculares de colores y blancos de cordoncillo (1803) (Palomeque, 1989, p. 183).

En relación con las prácticas relacionadas al textil entre fines del siglo XIX e inicios del siglo XX, presentamos lo expuesto por viajeros y expedicionarios que llegaban —en algunos casos a través de misiones diplomáticas - a este sector de la Puna argentina (Benedetti, 2002, 2005, 2009). En su paso entre 1880 y 1884, Alejandro Bertrand, narra lo siguiente:

El único chileno residente allí es el actual inspector del distrito, don Angel Custodio Villalobos; tiene un pequeño comercio de géneros, tabaco, maíz, aguardiente 
y vino que trae de Belén cuyos artículos pagan los indios con pieles de vicuña o lana hilada por sus mujeres. Los indios son tan poco industriosos que no fabrican por sí mismos todos sus tejidos de lana, sino que traen los más finos de la Argentina. Antofagasta es frecuentada por los arrieros que internan burros a Bolivia, haciéndolas pastar en los potreros de cordillera (Bertrand, 1885, p. 41).

Por su parte, Daniel Cerri en su paso por el lugar describía algunas prácticas de vestir de los pobladores antofagasteños:

\begin{abstract}
Los hombres visten sacos y pantalones cortos, sombreros blancos o simplemente vincha. Las mujeres enaguas con corpiño en número de tres o cuatro según los fríos. Calzan guantes y usan medias gruesas de lana y una especie de sandalias que llaman ojotas. Todos estos vestidos son confeccionados por las mujeres, que son trabajadoras y hábiles para tejer e hilar lana de oveja, Ilama, vicuña y cabra. Estas mujeres son muy laboriosas, tejen en un telar rústico colocado a la sombra de alguna peña, confeccionan los potajes para sus alimentos, lavan y cuidan de los rebaños en ausencia de los hombres que van a la caza. Los indígenas para mordiente de las tinturas que aplican a sus tejidos utilizan alumbre, se pueden ver minas de alumbre alrededor del volcán negro, en cercanía a la laguna de Antofagasta (Cerri, 1903, p. 143).
\end{abstract}

La información aquí presentada será retomada más adelante para discutir acerca de las materialidades textiles recuperadas en contextos de excavación. Con relación a la investigación vinculada a la práctica textil de momentos actuales, se cuenta con la información obtenida a partir del trabajo en archivos, la realización de entrevistas y la recopilación de cuentos y relatos orales de los pobladores locales (García y Rolandi, 2000, 2003).

\title{
Materialidad textil como espacio de autonomía
}

El textil, en tanto materialidad con efecto social, construye relaciones (Sillar, 2009) y a su vez refleja respuestas a discursos hegemónicos, particularmente en contextos de relaciones sociales asimétricas. Es interesante abordar el estudio del textil siguiendo la propuesta de Ingold (2007) cuando define las propiedades de los materiales como procesuales y relacionales, ya que no están objetivamente determinados ni subjetivamente imaginados, sino que son experimentados en la práctica. Cada propiedad, sostiene el autor, es una historia condensada, y "la descripción de las propiedades de los materiales es contar las historias de lo que les pasa a ellos a medida que fluyen, se mezclan y mutan" (Ingold, 2007, p. 14). Esta confluencia de historias en una misma materialidad puede mostrar respuestas activas ante una nueva realidad. Las relaciones de poder asimétricas en el área de estudio y en el contexto estatal de los siglos XIX y XX nos permiten indagar en las posibles estrategias de reproducción social (Bourdieu, 2011) que son generadas a partir de las prácticas sociales vinculadas al textil.

Según Scott (1990), las estructuras de dominación hacen surgir, si el resto de las condiciones no cambian, reacciones y estrategias de resistencia. Siguiendo al autor

los colonizados normalmente no se atreverían a rechazar de manera abierta las condiciones de subordinación, muy probablemente crearán y defenderán a escondidas un espacio social en el cual se podrá expresar una disidencia marginal al discurso oficial de la relaciones de poder (Scott, 1990, p. 20).

En este sentido, nos proponemos reflexionar para un contexto republicano sobre la persistencia de las prácticas textiles: ¿las puneñas y los puneños negociaron en sus 
prácticas diarias, ya sea de manera intencional o involuntaria, la propia identidad social dentro de un sistema jerárquico?

Silliman (2001) plantea el concepto de políticas prácticas y las define como la negociación de políticas de posición e identidad social en las prácticas diarias. Éste considera a los actos de residencia tan importantes como a los actos de resistencia. En palabras del autor "By acts of residence I mean the attempts of individuals to stake out a claim in their social worlds, even under contexts of oppression and domination, that may have little to do with outright or even impromptu resistance." (Silliman, 2001, pp. 194-195). Como Scott (1990) y otros se han encargado de mostrar, los individuos frecuentemente organizan sus vidas diarias no alrededor de la idea de tomar un lugar sino de forjar su residencia allí: "Without leaving the place where he [sic] has no choice but to live and which lays down its law for him, he establishes within it a degree of plurality and creativity" (De Certeau, 1984, p. 30). "Plurality and creativity are what give the archaeological record of colonialism such theoretical promise" (Silliman, 2001, p. 195). En relación con lo planteado por estos autores, entendemos que en estas prácticas cotidianas se da la posibilidad de la implementación por parte de la población puneña, de la pluralidad y la creatividad en los espacios de residencia. Esta creatividad posibilita "el escape" a la norma social llevando adelante actos de resistencia dentro de un contexto opresor. Estas formas de residir permiten la reproducción social de prácticas propias que dan lugar a la persistencia de ciertas materialidades en contextos sociales que buscan negar la pluralidad cultural a través de proyectos asimilacioncitas y homogeneizadores (Boccara, 2002). Es por esto que en los espacios cotidianos, de residencia, encontramos indicadores de las diversas formas de habitar a partir del estudio del registro del mundo material. Por ejemplo, las sociedades agropastoriles de la puna meridional muestran una flexibilidad en sus economías productivas - previa a la colonización europea- que se constituyen como respuesta ante nuevos contextos sociales. Planteamos que las sociedades puneñas continúan reproduciendo una lógica local, la cual incorpora nuevos elementos a lo preexistente, combinando economías de subsistencia. En este sentido, para el Periodo Formativo Escola (2002) plantea el reaseguro de la subsistencia entre las sociedades agropastoriles. Entre este tipo de sociedad habría primado una economía mixta. Es decir, la coexistencia de la caza especializada de camélidos silvestres con el pastoreo de camélidos (Lama glama, Lama guanicoe) (Urquiza y Aschero, 2014). Otros indicadores materiales que combinan saberes previos con los nuevos conocimientos se registran en las manifestaciones artísticas. El arte rupestre muestra secuencias de producción de distintas temporalidades coexistiendo en un mismo panel. En algunos casos, los motivos se encuentran superpuestos a modo de imposición iconográfica (Martel y Aschero, 2007), mientras que en otros, los ejecutores aprovechan los espacios vacíos, articulando la composición con las representaciones previas. "Es allí donde cada nuevo ejecutor fue reviviendo lo pasado y resignificándolo - a su modoen una nueva realidad" (Martel, Curletto y Del Bel, 2012, p. 150). Consideramos que la idea de Escola (2002) de reaseguro de la subsistencia corresponde a una lógica propiamente puneña con raigambre prehispánica. Ésta, en contexto colonial y republicano, permitiría también el "reaseguro" de la reproducción social de un grupo.

La articulación y reconfiguración de prácticas preexistentes con las nuevas también lo observamos en la materialidad textil. Las prácticas prehispánicas como el manejo de fibras para la elaboración de cordeles, la confección local de telas de calada, la utilización de técnicas para la elaboración de prendas de vestir y bolsas contenedoras en faz de urdimbre y faz de trama y la evidencia de teñidos por reserva, se combinan en nuevos contextos sociopolíticos con otras materialidades vinculadas a las circulación de telas e hilos industriales, bienes propios de la modernidad. Creemos que esta articulación también podría darse en la conformación de la identidad social de un grupo. 
La producción y/o consumo del textil en diversas esferas sociales da cuenta de la confluencia en una materialidad de técnicas, saberes, significados, recursos e historias interconectadas; es por ello que proponemos a la materialidad textil en el mundo andino como elemento distintivo de reproducción social, material y simbólica en contextos de profundas transformaciones. Al articular y entrelazar las tecnologías previas con las nuevas se construye un espacio de autonomía como una forma de residir. Los espacios de autonomía de un grupo fortalecen los lazos familiares e intercomunitarios de manera tal que se convierten en una toma de posición y una forma de negociación en contextos de relaciones asimétricas (Hutson, 2002).

En la confección tanto del cordel como del textil, de fibra animal por ejemplo, se conjugan una serie de elementos naturales y culturales, saberes históricos y relaciones sociales humanas y entre hombres y mujeres y otros animales. También se articulan el pastor o la pastora puneña que cuida de la hacienda, la realización de la esquila con sus propias manos (en determinadas épocas del año), la ardua tarea de separar y limpiar el vellón para luego hilar y torcer, y por último, la confección del tejido. Una multiplicidad de factores involucrados en la confección del textil que a su vez tienen significados complejos cuando, como producto de esa práctica, participan en distintas esferas sociales y en determinados contextos socio-históricos (Arnold y Espejo, 2013; Martinez, 2017; Méndez, 2009; Rolandi de Perrot y Jiménez de Pupareli, 1983-1985; Teves, 2011; entre otros).

Para Arnold y Espejo (2013) el textil en el mundo andino constituye un soporte material para articular subjetividades propias e identidades ajenas en nuevas combinaciones. Centrada en esta particularidad, la práctica textil se configura como un soporte material de la memoria social del grupo local. En este contexto específico,
el textil sirve como un instrumento de documentación de la historia y de la vivencia del grupo, de las pertenencias del grupo social (en términos de tierras y recursos naturales), de las actividades laborales que sostienen su producción, y las nuevas oportunidades a su disposición (Arnold y Espejo, 2013, p. 316).

En vista de lo expuesto, es que nos permitimos reflexionar sobre la reformulación y reconfiguración identitaria por parte de los puneños: ¿se relaciona ésta con la mixtura de prácticas preexistentes y novedosas para generar "lo propio"?, ¿puede "lo propio" representar las trayectorias históricas de las sociedades colonizadas?, ¿ son la creatividad y el ingenio una respuesta al poder? Planteamos que las poblaciones puneñas construyen espacios de negociación a través de la mixtura y articulación de elementos novedosos y tradicionales en sus prácticas cotidianas.

\section{Contexto arqueológico. Peñas Coloradas 3-cumbre}

El sitio arqueológico se ubica en la margen sur del curso inferior del río Las Pitas, afluente del río principal Punilla en la localidad antofagasteña, provincia de Catamarca. El mismo se conforma por distintas estructuras arquitectónicas superficiales y subsuperficiales que se emplazan en la cumbre de una de las cuatro peñas tabulares de ignimbritas que forman parte de la localidad Peñas Coloradas (Figura 4).

Cohen (2014) interpreta al sitio Peñas Coloradas 3-cumbre (en adelante PC3-c) como un punto de control visual en la dinámica de vida del entorno. Según la investigadora, se encuentra dotado de un poder social con la conservación de autonomías locales en un sector que se consideraba periferia. El análisis formal de la arquitectura, los contextos arqueológicos y los fechados radiocarbónicos permitieron asignar las ocupaciones a momentos Tardíos e Incas con reutilización en tiempos republicanos. 


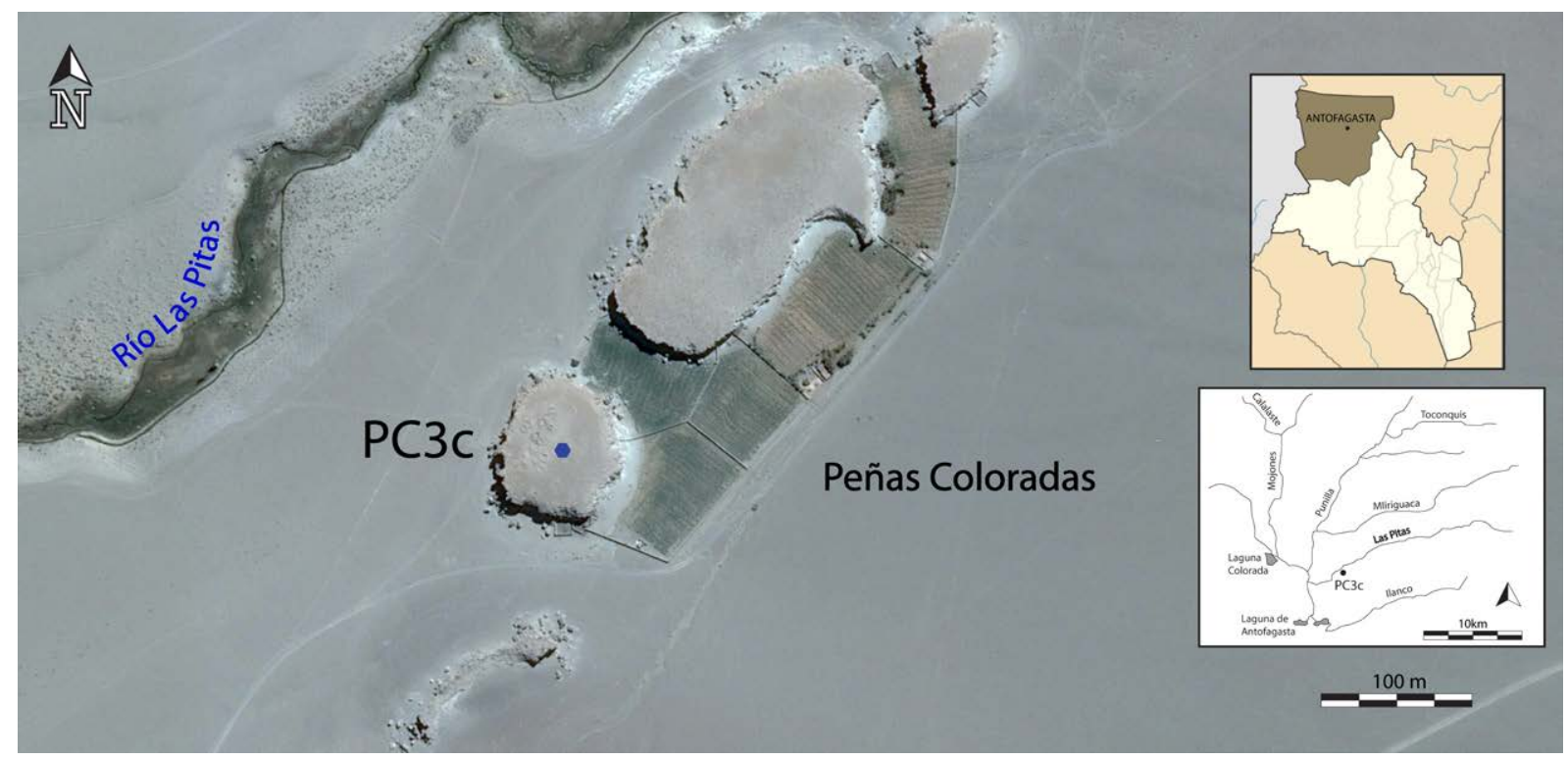

Figura 4. Imagen satelital de la localidad Peñas Coloradas y ubicación del sitio Peñas Coloradas 3-cumbre (PC3-C) (fuente: Google Earth).

A su vez, PC3-c forma parte de una localidad marcada y significada por una gran concentración de manifestaciones plásticas con grabados de larga data y cuyas expresiones alcanzan tiempos históricos (Aschero, 1999). La muestra analizada en este caso proviene de una de las diversas modalidades constructivas que se construyeron en la cima de la peña columnar de ignimbrita, en el tipo falsa bóveda (que corresponden a las estructuras I, II y XIII). Particularmente, la estructura que contenía el material aquí estudiado es la XIII, ubicada al Suroeste de la cumbre de la peña. Cohen (2014) asocia las estructuras de falsa bóveda superficial y cámaras subterráneas a prácticas de depósito que comprendieron materias primas (vellones, cordeles, minerales), herramientas (agujas, torteros, artefactos líticos, piezas cerámicas, bolsas de tejidos vegetales, entre otros), alimentos (partes animales, endocarpos de Prosopis nigra y Prosopis alba) y posibles objetos de ofrendas y/o ajuares funerarios (torteros, vincha de cestería y atados rituales) (Cohen, 2010; Cohen y Martinez, 2012; Martinez, 2012 en Cohen, 2014).

Según la autora, la estructura XIII evidencia una intencionalidad de explícita exposición visual dentro de la cumbre. En esta falsa bóveda se realizaron nueve sondeos de 0.50 $\mathrm{m}$ x $0.50 \mathrm{~m}$ con una orientación Norte-Sur. En la misma se hallaron cordeles y textiles de manufactura artesanal e industrial, junto a una aguja de espina de cactácea, un fragmento de cestería, un ovillo de hilo de algodón, vellones, cueros y una hoja de cuchillo de acero. Se realizó una datación radiocarbónica sobre el fragmento de cestería recuperado en el sondeo 1, capa 1 que arrojó un fechado de 1720-1820 cal. d.C. (Cohen, 2014).

En las entrevistas realizadas a tejedoras y pastoras de la localidad de Antofagasta de la Sierra en el año 2009, documentamos las prácticas sociales vinculadas a las materialidades textiles (Martinez, 2012, 2013). Aquí nos interesa remarcar la información obtenida sobre los lienzos. La pastora A. V. (febrero 2009) nos narraba lo siguiente:

Por lo menos yo cuando le he conocido a la abuelita ella hacia una telita así rayadita diremos así cuadritos tejiditos, urdían así y lo tejían casi así y lo hacían así y se hacían una falda y cuando conocían se iban a los Valles y traían una bolsa que 
tenía harina era como un lienzo que decían ellos y esos hacían ellos, compraban hacían y después lo deshacían y se hacia la ropa interior. Eran como si fueran de algodón esas bolsas, yo también me habré puesto una camisa que me habrá hecho mi abuelita. Ellos traían así, porque ellos vendían así la harina diremos en una bolsa que decían ellos de lienzo. Ellos traían y esto lo deshacían y hacían la interior.

Es significativo destacar la existencia de reciclado o transformación de los textiles. Lo narrado durante la entrevista deja entrever cómo el lienzo circulaba como contenedor de alimentos primero y luego como otra forma de consumo personal, a modo de prenda o vestimenta. Otro elemento a mencionar es su procedencia no local, ya que las telas eran traídas desde los valles, en los viajes realizados a lomo de mula ${ }^{1}$.

\section{Materiales y métodos}

En este artículo presentamos como material de estudio sólo las piezas textiles recuperadas en la falsa bóveda XIII (Figura 5). La muestra textil histórica total del sitio PC3-c corresponde a 42 elementos, mientras que la procedente de la estructura XIII cuenta con 34 piezas. Las características generales de los textiles hallados en el sitio están dadas por la diversidad de materias primas, texturas, colores, técnicas de confección y dimensiones. Aunque la muestra presenta un buen estado de conservación, no registra piezas enteras. Los modos de confección entre los textiles artesanales e industriales varían. Los primeros fueron elaborados por tejedoras de una manera manual, ya sea en telar o tejidos con agujas, mientras que los segundos se confeccionaron por medio de telares mecánicos (Martínez, 2012, 2017).

Tanto el estudio del material textil como el de cordelería vinculada estructuralmente a los mismos abarcaron dos etapas, una correspondiente al análisis cualitativo y la otra, al análisis cuantitativo. Siguiendo los lineamientos metodológicos de López Campeny (2001) y Salerno (2006), entendemos por textil a toda combinación de hilos entrecruzados ya sean de fibra natural — de proteína o de celulosa- y/o de fibra sintética, confeccionado de forma artesanal y/o industrial. Los cordeles son el producto final de la combinación, mediante la torsión de dos hilos y los hilos, a su vez, son el resultado de la acción de la primera torsión o hilado de un conjunto de fibras (animales o vegetales) (López Campeny, 2001).

En cuanto al análisis cualitativo nos basamos en la observación y estudio de cada pieza procedente de la estructura XIII y en el relevamiento de una serie de atributos morfológicos y tecnológicos que se consideraron relevantes para la descripción textil. Los datos se volcaron en fichas descriptivas y en una base de datos. ${ }^{2}$ Por su parte, en el análisis cuantitativo se combinaron los atributos morfológicos y tecnológicos analizados en estadística descriptiva. Los atributos escogidos para su presentación son: técnica de manufactura, estructura y tipo textil, materia prima, diseño y color, elementos teñidos, tipos de hilados y dirección de torsión. Las últimas tres variables técnicas se relacionan con los cordeles que componen las piezas textiles (costura de unión, de reparación o decorativa) (Tabla 1). Nos parece importante destacar que a partir de los atributos tecnológicos, técnica de manufactura y materia prima podemos asignar una cronología relativa a las piezas.

En primera instancia definimos la técnica de manufactura, artesanal y/o industrial. El desarrollo de la manufactura industrial entre 1780 y 1880 d.C. fue crucial en la configuración de la industria textil en el mundo moderno ${ }^{3}$ (Williams, 1993). En la muestra analizada, todas las telas de origen industrial o los lienzos de origen artesanal se confeccionaron con fibra natural vegetal, algodón. No se registraron fibras sintéticas, la difusión de estas últimas no tuvo lugar hasta fines del siglo XIX (Salerno, 2006). En
1. Para profundizar en los viajes realizados en contexto republicano en Antofagasta de la Sierra desde un estudio arqueológico ver Zamora (2019).

\author{
2. Para un mayor detalle de \\ la metodología utilizada y las \\ variables seleccionadas para la \\ caracterización de la muestra textil \\ histórica ver Martinez (2017).
}

3. Con la creación del primer telar mecánico (1796), la primera máquina de Jacqard (1804) y el invento de la primera máquina Singer (1850). 


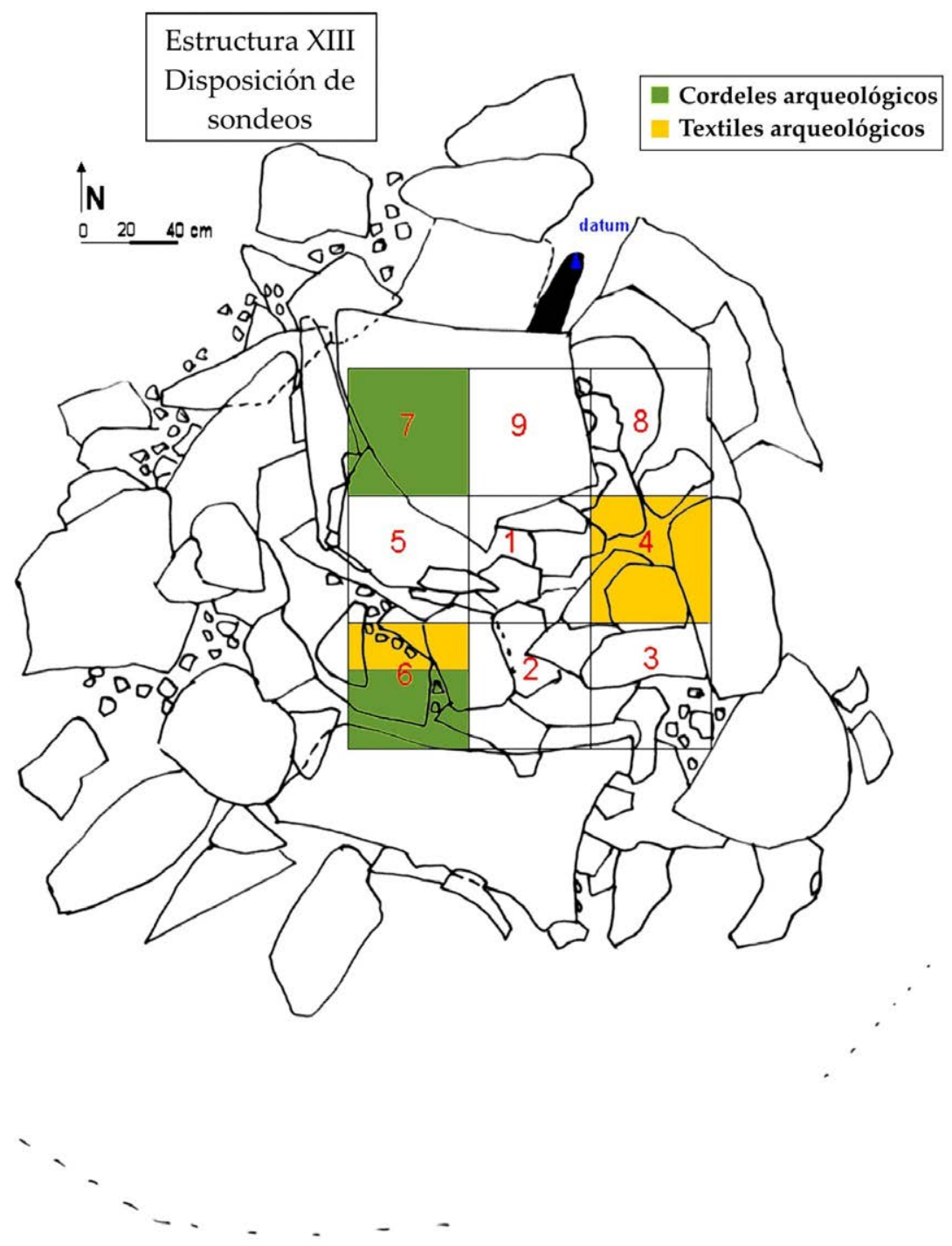

Figura 5. Planta de excavación de falsa bóveda XIII, de PC 3-c. Distribución de la evidencia textil recuperada en los distintos sondeos (Imagen modificada de Cohen, 2010).

\begin{tabular}{|l|c|c|}
\hline Atributos tecnológicos analizados & Textiles & Cordeles \\
\hline Técnica de manufactura & $\mathrm{x}$ & $\mathrm{x}$ \\
Materia prima & $\mathrm{x}$ & $\mathrm{x}$ \\
Estructura, tipo y variedad de tejido & $\mathrm{x}$ & - \\
Tipo de hilado & - & $\mathrm{x}$ \\
Dirección de torsión & - & $\mathrm{x}$ \\
Elemento teñidos & $\mathrm{x}$ & $\mathrm{x}$ \\
Diseño y color & $\mathrm{x}$ & $\mathrm{x}$ \\
\hline
\end{tabular}

Tabla 1. Atributos tecno-morfológicos registrados en los textiles y cordeles. 
cuanto a otros tipos de indicadores sintéticos utilizados en la producción europea textil en las primeras décadas del siglo XIX se destaca la anilina, existiendo a finales de 1850 una amplia gama de colores (Williams, 1993).

En relación con la materia prima contemplamos el origen de la fibra (natural o artificial). En el caso de fibra natural señalamos si esta es animal o vegetal. Se trató de una identificación macroscópica y para la descripción se utilizó una muestra de referencia.

En cuanto a la estructura y tipo textil, la primera se vincula a la relación espacial y numérica entre los elementos (tramas y urdimbres) que conforman el textil (Emery, 1966). La forma en que se clasifican las diferentes estructuras de un textil depende de la disposición y relación que se da entre urdimbres y tramas. Salerno (2006) define a los textiles planos (llanos, de calada, telar o simple) como dos o más conjuntos de hilos, urdimbre y trama, que se entrelazan perpendicularmente en un telar. Si bien estos dispositivos sufrieron numerosas modificaciones a lo largo del tiempo, sus operaciones básicas siguen siendo las mismas: sostener los hilos de urdimbre entre dos soportes, de forma de fijarlos y que sirvan de estructura, e insertar los hilos móviles de trama por encima y debajo de los de urdimbre, compactándolos para formar la tela (Salerno, 2006).

Otro tipo de tejidos son los denominados tejidos en punto. Su elaboración demanda la utilización de agujas, que se utilizan para formar mallas. En estas, uno o más hilos dan lugar a una serie de bucles o loops entrelazados. Las telas que se obtienen son elásticas, porosas y resistentes (Deslandres, 1985; Hollen, Saddler y Langford, 2001; Turneau, 1993). Los tejidos de punto pueden ser por urdimbre o por trama, los primeros solo pueden ser obtenidos mediante procedimiento industrial y los segundos pueden ser elaborados por medio de técnicas tanto artesanales como industriales (Salerno, 2006). El tejido de punto es por lo general más elástico que los otros tipos de tejidos ya que las mallas que lo conforman pueden agrandarse a costa de las entremallas y de su anchura si es estirado en sentido vertical y aumentar su tamaño en sentido horizontal, agachándose las mallas y por tanto perdiendo altura. En ambos casos, al cesar las tensiones que provocan los cambios de dimensiones, el tejido tiende a regresar a su tamaño y forma original (Ruiz Espinoza, 2013). Las máquinas utilizadas para la fabricación de tejidos de punto por trama, llamadas también máquinas tricotosas rectilíneas, utilizan las agujas de lengüeta de una cabeza. Este tipo de agujas no apareció hasta 1855 d.C. debido a Towswnd, dando lugar a que nacieran las máquinas tricotosas. En cuanto al tejido de punto por urdimbre, se trata de un único hilo que avanza en sentido vertical. Este tipo de punto sólo puede realizarse mediante procedimientos industriales (Salerno, 2006). El género de punto en su forma más simple o "punto por trama" consta de filas de bucles construidas a partir de un hilo continuo que avanza de un lado a otro de la tela o pieza, construyendo la malla por medio de agujas de tipo ganchillo o prensa (González, 2017).

En cuanto al atributo técnico de diseño, se identificó la técnica decorativa y se describieron ubicación y principales características de la misma. Para la determinación del color se utilizaron como referencia las Tablas Munsell Soil Color Chart (Munsell Color, 2009) y Munsell Color Charts for Plant Tissues (Munsell Color, 1977). Se consignó como diseño liso cuando no se observó técnica decorativa.

En el caso de identificar costuras se tomaron los siguientes datos: ubicación, descripción del tipo de costura (de unión, decorativa o de reparación) y medición de la extensión de la misma (longitud y ancho). En cuanto al análisis de cordeles presentes en las piezas textiles se detalló el tipo y la dirección de hilado. Cabe señalar que existen únicamente dos tipos posibles de dirección del hilado, la torsión y la retorsión, hacia la derecha o hacia la izquierda. Cada una de estas direcciones se designa convencionalmente con el 
4. Se lo considera foráneo porque no se produce en nuestra área de estudio, llega como producto acabado. Desde la cultura material y desde las fuentes históricas

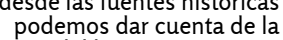
circulación del lienzo en contexto republicano. 5. Una basta puede ser entendida como la sección de un hilo que cruza dos o más hilos perpendiculares (Deslandres, 1985;

Espinoza y Gruzmacher, 2002; Hollen et al., 2001)
6. Como nos mencionaron las pastoras y tejedoras en las entrevistas realizadas en la localidad (ver Martinez, 2012). sistema de letras $\mathrm{S}$ y Z, respectivamente. El tipo de hilado se clasifica en simples, moliné o mishmido (cf. Martinez, 2017). Asimismo, se describió el color de los elementos teñidos.

\section{Resultados}

Los resultados del estudio integral de cordeles y textiles y su contexto material, procedentes de las excavaciones sistemáticas de todas las estructuras abovedadas de PC 3-c, se dieron a conocer en otro trabajo (Martinez, 2017). Tal como mencionamos anteriormente en este artículo presentamos como material de estudio sólo las piezas textiles recuperados en la falsa bóveda XIII (Figura 5).

Los textiles recuperados en esta estructura arquitectónica corresponden al 81\% ( $\mathrm{n}=34)$ del total de la muestra procedente de las falsas bóvedas y la cista del sitio Peñas Coloradas 3 cumbre $(n=42)$. De los textiles nos interesa resaltar dos variables tecnológicas como indicadores cronológicos - la técnica de manufactura y la materia prima-y a su vez, como mencionamos con anterioridad, la presencia en una misma pieza de tradiciones tecnológicas textiles diferentes (Tabla 2). Por este motivo, seleccionamos para su estudio las piezas elaboradas a partir de una manufactura industrial y artesanal con fibra de algodón, con la singularidad de que ciertas materialidades presentan combinaciones de tradiciones tecnológicas, que desarrollaremos en esta sección.

Dentro del conjunto de textiles recuperados en esta estructura abovedada más del $80 \%$ $(\mathrm{n}=28)$ corresponde a confecciones de manufactura industrial. Del total de la muestra analizada en este trabajo $(\mathrm{n}=34)$ más del $52 \%(\mathrm{n}=18)$ presenta una confluencia de tradiciones tecnológicas. Por un lado, en lo que refiere a la técnica de confección del textil, se registraron telas industriales que presentan costuras con cordeles artesanales combinados en una misma pieza. Y por otro lado, se da una conjunción de materia primas utilizadas: estructura textil elaborada con fibra de algodón y costuras realizadas con fibra animal. Es decir, observamos la mixtura de materias primas y técnicas de confección diferentes como son los casos de lienzo de fibra de algodón (foráneo) ${ }^{4}$ con cordeles de lana (autóctono) en sus costuras de unión, reparación y/o decoración (Figura 6).

En relación con los elementos que se combinan para formar la tela, identificamos sólo un $7 \%(n=3)$ con estructura de tipo sarga: cada uno de los hilos de trama o urdimbre hace una basta sobre dos o más hilos en la dirección opuesta ${ }^{5}$. El punto de ligadura se mueve en una progresión de uno a la derecha o izquierda de los hilos subsiguientes. Ello permite la formación de una diagonal o "espiga" característica (Hollen et al., 2001, en Salerno, 2006). En nuestra muestra identificamos tres piezas de algodón confeccionadas de forma mecánica en tejido de punto por trama y una única pieza realizada en tejido de punto por urdimbre. Las telas de tejido de punto por trama no presentan proceso de tinción, y una de ellas presenta una costura de cordel artesanal de color natural oscuro. Dichas telas confeccionadas a partir de tejido en punto por trama corresponden a la variedad de jersey simple con columnas que corren en sentido longitudinal y pasadas en sentido transversal (Salerno, 2006). El resto de las piezas textiles recuperadas en la falsa bóveda presentan estructura plana o llana (ver Martinez, 2017).

En cuanto a los diseños y color, más del $90 \%(\mathrm{n}=38)$ son lisas y corresponden a colores plenos, mientras que más del $50 \%(\mathrm{n}=21)$ registran colores claros predominando el 10 YR 7/3 y 10 YR 8/3. Estas tonalidades conciernen a las fibras de algodón, materia prima utilizada para la confección de las telas que no fueron sometidas a procesos de tinción natural (con monte) ${ }^{6}$ ni sintética. En cuanto a los colores de las fibras teñidas de las telas industriales registramos el predominio del azul, rojo y bordó. Como ya se mencionó, los tintes sintéticos aparecieron en 1850 d.C. a partir del uso de anilina (Williams, 1993). 


\begin{tabular}{|c|c|c|c|c|c|c|c|c|}
\hline \multirow{2}{*}{$\begin{array}{l}\text { PC 3-c. Estructura XIII } \\
\text { Variabilidad }\end{array}$} & \multicolumn{2}{|c|}{$\begin{array}{l}\text { Textiles artesanales de } \\
\text { algodón con costura de } \\
\text { fibra animal }\end{array}$} & \multicolumn{2}{|c|}{$\begin{array}{l}\text { Textiles artesanales de } \\
\text { fibra animal sin costura }\end{array}$} & \multicolumn{2}{|c|}{$\begin{array}{l}\text { Textiles industriales de } \\
\text { algodón con costura } \\
\text { fibra animal }\end{array}$} & \multicolumn{2}{|c|}{$\begin{array}{c}\text { Textiles industriales de } \\
\text { algodón sin costura fibra } \\
\text { animal }\end{array}$} \\
\hline & Lienzo & Otros & Lienzo & Otros & Lienzo & Otros & Lienzo & Otros \\
\hline$n$ & 3 & 1 & - & 2 & 8 & 10 & 8 & 2 \\
\hline$\%$ & $9 \%$ & $3 \%$ & - & $6 \%$ & $23,5 \%$ & $29 \%$ & $23,5 \%$ & $6 \%$ \\
\hline $\begin{array}{l}\text { Total de la muestra } \\
\text { analizada }(n=)\end{array}$ & \multicolumn{2}{|c|}{34} & \multicolumn{2}{|c|}{34} & \multicolumn{2}{|c|}{34} & \multicolumn{2}{|c|}{34} \\
\hline
\end{tabular}

Tabla 2. Textiles recuperados en las excavaciones de la Falsa bóveda XIII en PC3-c.

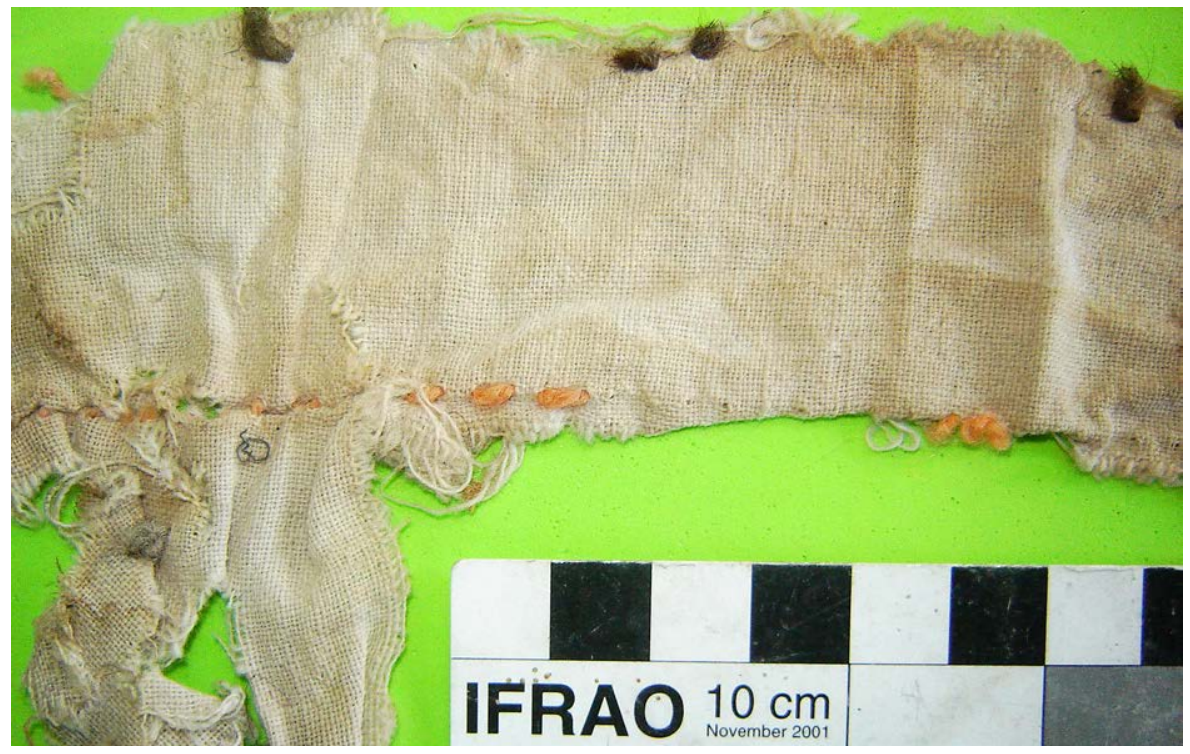

Figura 6. Lienzo de algodón sin proceso de tinción. Registra costuras de cordeles artesanales teñidos y sin teñir.

Es importante destacar que si bien un alto porcentaje de las telas no presentan procesos de tinción y predominan los colores claros, los hilados torsionados que forman parte de las costuras artesanales exhiben colores contrastantes con respecto a la tela que cosieron, repararon, unieron y/o decoraron. En caso de tinción, los colores registrados fueron rojos, anaranjados y violetas, mientras que en aquéllos casos donde no hay tinción, las fibras oscuras que conforman el cordel se destacan visiblemente sobre las estructuras textiles claras (Figura 6 y 7). Sólo una de las piezas analizadas que corresponde a un lienzo elaborado en telar artesanal (color 10 YR 8/3) que parecería ser una pequeña bolsa contenedora, muestra una costura de unión de cordel artesanal de fibra natural animal de una tonalidad semejante a la tela (color 10 YR 8/2). Sin embargo, cabe destacar que corresponde a un cordel de lana; lienzo y cordel en la costura constituyen materias primas diferentes (Figura 8). Este ejemplar se encontró próximo al fragmento de cestería datado en $194 \pm 38$ AP (1720-1820 cal. $2 \sigma$ d.C.), es decir, al siglo XVIII y principios del siglo XIX. Esto nos permite plantear alguna posible relación entre la combinación tanto de cordeles artesanales de colores llamativos en textiles industriales de fibra de algodón -que muestran una clara contrastación - como de los cordeles artesanales que se mimetizan con los textiles presentando una tonalidad similar y una posible asignación cronológica a este tipo de elecciones tecnológicas. Retomaremos este planteo más adelante.

Los tipos de hilado identificados en las costuras corresponden sólo al ejemplar simple. Se trata de cordeles que presentan torsión de dos cabos o hilos de idéntico color, 


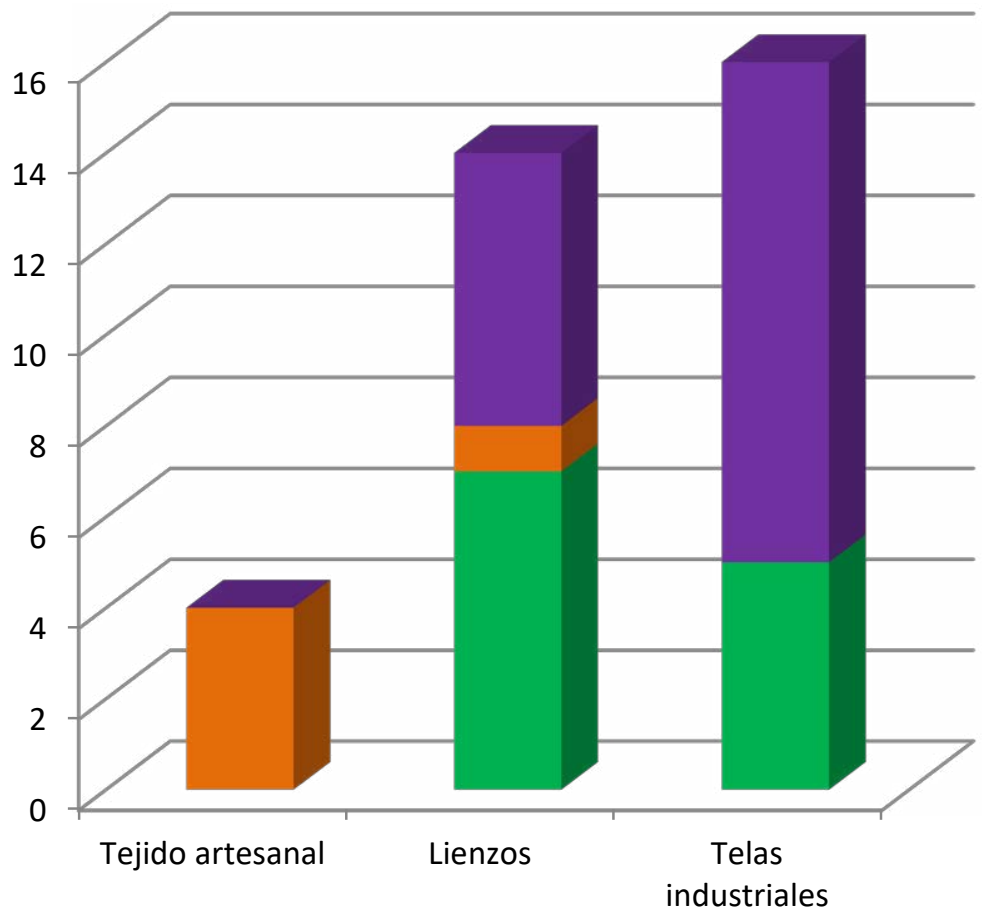

- Costura con hilo industrial

- Costura con cordel sin proceso de tinción

Costura con cordel con proceso de tinción

Figura 7. Detalles de las costuras con y sin proceso de tinción en las distintas telas y tejidos recuperados en la Estructura XIII.
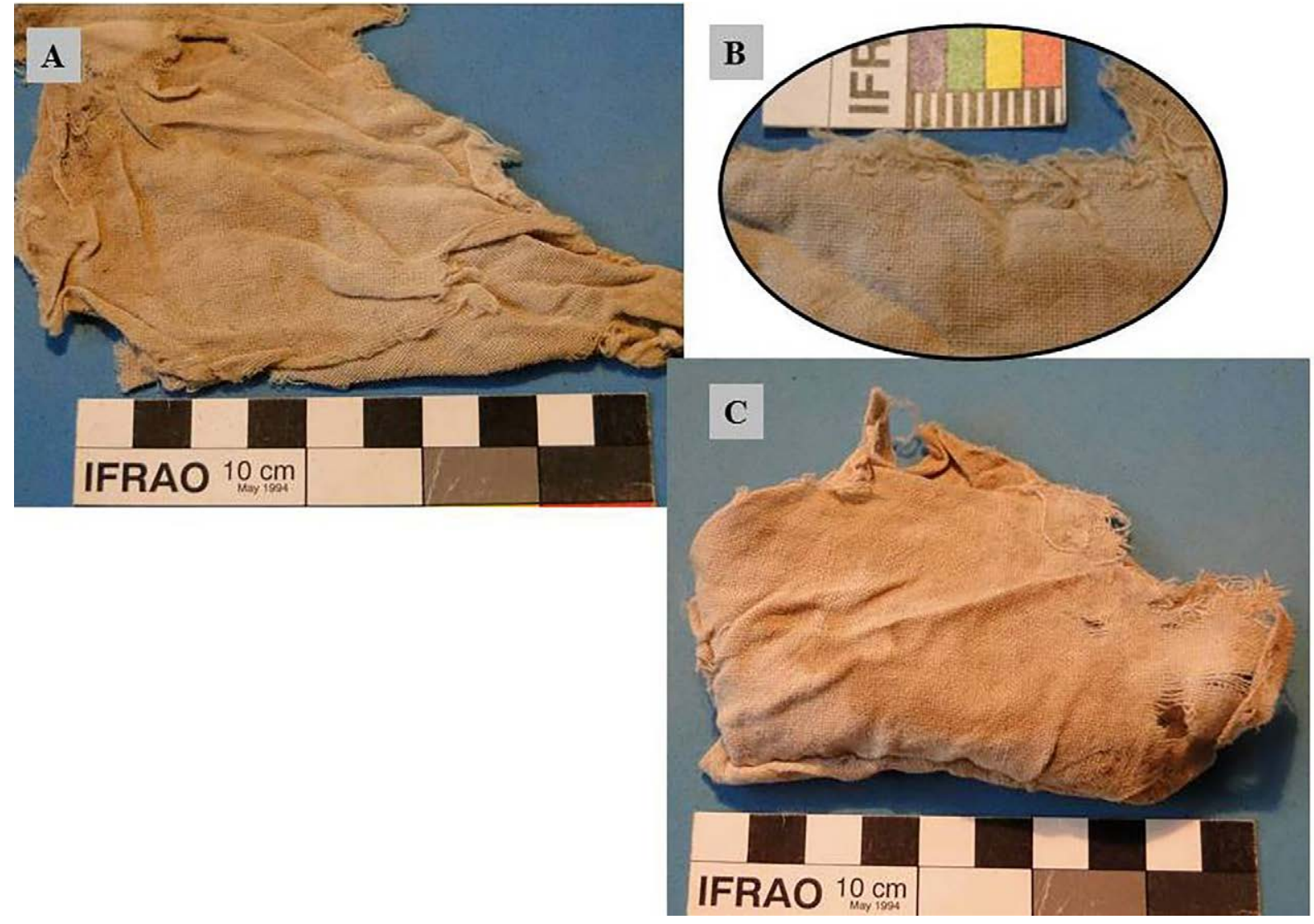

Figura 8. Bolsa de lienzo. Referencias: A) lado anverso de bolsa de lienzo con costura artesanal; B) detalle del cordel de costura de fibra animal, presenta el mismo color del tejido de fibra de algodón; $C$ ) lado reverso de la bolsa de lienzo. 
diámetro y materia prima (López Campeny, 2001; Martinez, 2017). Con respecto a la dirección de torsión final, los elementos teñidos tienen una torsión hacia la derecha. Sin embargo, los hilados sin tinción, con una sola excepción, registran una torsión final hacia la izquierda.

Del total de las piezas analizadas procedentes de la falsa bóveda XIII $(\mathrm{n}=34)$, el $80 \%$ corresponde a textiles confeccionados con manufactura industrial; este tipo de producción se conoce desde principios del siglo XIX en adelante, lo que nos da un rango cronológico para esta evidencia. En cuanto al consumo de lienzos, representan más del $50 \%$ del conjunto. Sin embargo a partir del cruce de diferentes variables tecnológicas se pudo observar que el $10 \%$ de los lienzos fueron confeccionados en telar artesanal.

Ahora bien, con respecto a los fragmentos de lienzo reparados con cordel de lana $(\mathrm{n}=11 ; 32,35 \%)$, destacaremos una pieza en particular en la que identificamos letras de molde color rojo impresas como diseño que, por la fragmentación de la tela, no pudieron ser asignadas a alguna letra del alfabeto en particular (Figura 9). Los lienzos presentan una apariencia fina y liviana, lo que podría representar confort a la hora de reciclar el costal en ropa interior, sumado a las cualidades de suavidad de la textura y liviandad. Estos registran costuras de unión, atributo morfológico relevante teniendo en cuenta lo narrado por pastoras y tejedoras que nos hablaron de deshacer las telas de lienzo para confeccionar vestimenta personal, su ropa interior. Los saberes compartidos por las tejedoras y pastoras - en este caso- recordando prácticas de vestir y de consumo de sus abuelas/os es un aporte interesante para comprender la historia de los objetos.

\section{Discusión: a la sombra de una Peña, textil como espacio de negociación}

Desde la materialidad textil buscamos mostrar el rol activo de los/las puneños/as en la construcción de su realidad, aún con un nuevo orden social que impuso nuevas reglas, normas, categorías y modos de producción. Siguiendo a Buscaglia (2011), es significativo reflexionar sobre las respuestas desde las prácticas cotidianas ante la imposición de políticas liberales. La autora propone que:

las prácticas de la vida cotidiana y la cultura material que se pone en juego en las mismas, pueden generar alternativas, imponer límites y/o alterar el orden colonial sin que ello implique necesariamente una resistencia activa o una oposición abierta al mismo (Buscaglia, 2011, p. 70).

Como propuesta inicial abordamos la materialidad textil como espacios de negociación en contexto de cambios socio-políticos, tomando a los textiles, tal como proponen Arnold y Espejo (2013), como formas de respuestas a estos cambios y, a su vez, como parte de la memoria social y como soporte material para articular subjetividades propias e identidades ajenas en nuevas combinaciones. Sostenemos que una posible respuesta a estos cambios es a través de la creatividad, el ingenio y la vinculación de prácticas en un nuevo contexto por parte de la población puneña, articulando por ejemplo las materialidades preexistentes con nuevos recursos que se vinculan a las nuevas formas de consumo en la modernidad.

El Estado moderno con una bandera de modernidad e igualdad buscó anular la diversidad indígena y sus particularidades, el "indio" era el referente a negar (Martínez et al., 2002). Al considerar la reorganización territorial, administrativa y de modos de producción y consumo entre tantos cambios introducidos y la política de "disciplinamiento social" buscamos mostrar una de las formas de inserción de las puneñas y los puneños - a través de sus prácticas cotidianas- en esta nueva realidad. 


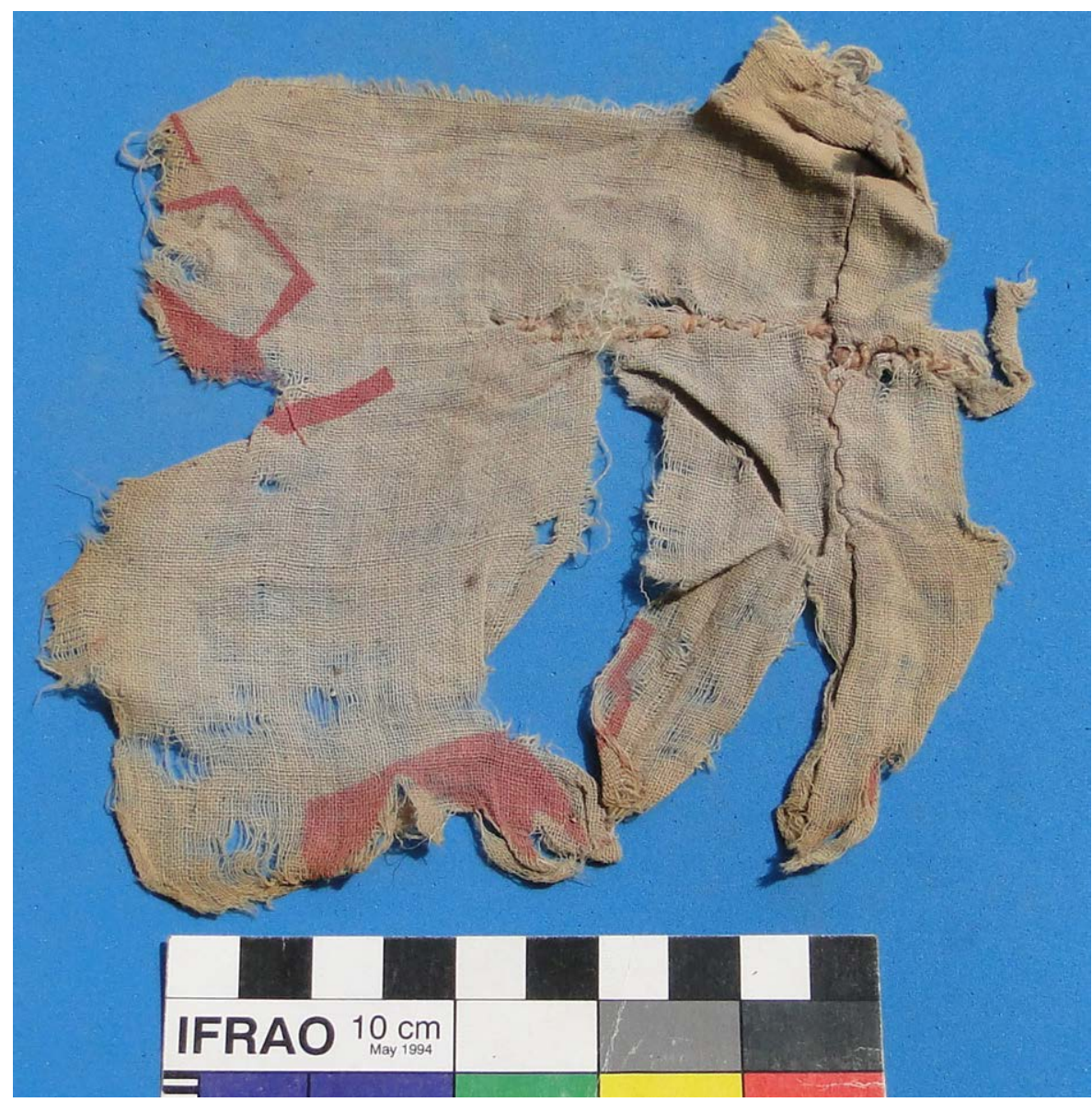

Figura 9. Tela de lienzo con letras impresas y costura con cordel artesanal teñido.

Proponemos entonces, que la materialidad textil refleja espacios de negociación como práctica identitaria y de la memoria social de esta comunidad. Dicha materialidad persiste, con trasformaciones, en un área de estudio con una fuerte tradición de textilería prehispánica como lo demuestran las investigaciones arqueológicas.

Según la información relevada en las primeras décadas de 1800 d.C. vemos la circulación de lienzos en los valles y la producción de los mismos a partir del tejido de las fibras de algodón en los telares de las casas de los pobladores. A su vez, hacia 1900 d.C. en Antofagasta de la Sierra las mujeres hilaban con lana de oveja, llama y vicuña de sus propias haciendas y tejían en su telar rústico a la sombra de una peña. Prácticas que nos hablan de consumo, producción y formas de habitar en tiempos republicanos; eso que en los valles sucedía en la patio de sus casas, en nuestra área de estudio ocurría a la sombra de una Peña.

Desde la arqueología, a partir del análisis aquí presentado, aportamos a estas prácticas vinculadas a la producción, consumo y elección de lo textil en un contexto republicano, en el cual observamos una mixtura de técnicas de manufacturas, de materias primas y de colores contrastantes en determinadas piezas textiles. Asumimos que el textil, en tanto materialidad con efecto social, construye relaciones a través de todos los componentes involucrados en su elaboración - como lo mencionamos con anterioridad- a la vez que refleja respuestas a discursos hegemónicos en contextos de relaciones asimétricas, posibilitando así la reproducción social (sensu Bourdieu, 2011).

El textil es entonces interpretado como espacio de autonomía de reproducción material y simbólica que cohesiona a la unidad familiar para su elaboración y a su vez los vincula 
con un pasado ancestral, con tantos años de producción, manejo y selección de fibra para tejer en este lugar de la puna meridional. Fortalece lazos no sólo en el presente sino también con el pasado, lo que genera autonomía para tomar decisiones y negociar en las relaciones desiguales.

En este sentido, a partir del análisis del conjunto de textiles históricos observamos la combinación de técnicas de manufacturas diferentes, materias primas y colores contrastantes y una marcada presencia de lienzos de algodón. Sin embargo, no hallamos evidencia material que indique la producción local de los lienzos, fibras e hilos de algodón, ni otros referentes materiales que remitan a su elaboración. Esto implica que no se tejían localmente, lo que se ve apoyado por la información obtenida acerca de la circulación de estos tejidos en las primeras décadas del siglo XIX o el reciclado de la tela industrial en el siglo XX. Esta información, vinculada a la producción local del lienzo en la Puna, debe operar como una hipótesis que debe continuar siendo trabajada si el registro material así lo permite.

Por otra parte, la evidencia material y contextual de la Estructura XIII nos muestra la presencia de artefactos vinculados a las prácticas textiles como agujas artesanales que, teniendo en cuenta la irregularidad de las puntadas y el tamaño de los orificios identificados en las telas y tejidos, apoyan una práctica manual. Es el caso de la aguja de espina de cactácea $^{7}$ (de ocho $\mathrm{cm}$ de largo), asociada a los textiles, y los restos de vellones de oveja y de llama. Nos parece importante destacar que, en relación con los modos de hacer, las tejedoras compartieron que las agujas de espina de cardón cortas se utilizaron para coser y las más largas para tejer (Martinez, 2012).

En cuanto a las materias primas identificadas, todas las telas y tejidos son de fibra natural de algodón. No se registraron fibras sintéticas, lo que concuerda con el rango temporal que estamos proponiendo para estas piezas. Es significativo recordar que las fibras artificiales circulan a fines del siglo XIX. Se destaca la presencia de cordeles realizados con una materia prima diferente (fibra animal) para realizar costuras. Planteamos, a partir del estudio de este conjunto textil histórico, que es una práctica propia de las/los puneñas/os esta forma de incorporar los cordeles de lana a las telas y tejidos de fibra de algodón, originados en sus haciendas. Esto es una forma de dejar plasmado un acto de residencia (sensu Silliman, 2001) a partir de la articulación y combinación de lo preexistente con lo nuevo, generando materialidades propias. En este caso se manifiesta con la reutilización y reciclado de telas ya confeccionadas, no producidas localmente, para transformarlas y utilizarlas según las necesidades de las puneñas y los puneños. Durante este quehacer, no hay un reemplazo de lo autóctono, sino una verdadera "mixtura" de tradiciones tecnológicas diferentes. La lógica de garantizar la reproducción social logrando una convivencia de prácticas sociales y saberes preexistentes con transformaciones propias de los nuevos contextos sociales es propiamente puneña y se registra en toda la secuencia ocupacional a partir de diversas líneas de evidencia en la Quebrada de Las Pitas (Aschero y Hocsman, 2011; Babot, 2006; Cohen, 2014; González Baroni, 2013; López Campeny, 2009; Martel y Aschero, 2007; Martel et al., 2012; Quiroga, 2015; Urquiza y Aschero, 2014, entre otros).

A su vez, remarcamos la utilización en ciertas materialidades textiles de cordeles de lana con colores contrastantes, en algunos casos teñidos y en otros sin proceso de tinción, pero en este último caso eligiendo fibras oscuras en tejidos claros o fibras claras en telas oscuras. Con respecto a esto, cabe preguntar si se trata de un uso oportunista o existe una intencionalidad por parte de los pobladores que responden a esta práctica.

Interpretamos que los lienzos de algodón que presentan costuras de lana con una tonalidad similar a la estructura textil serían de inicios del siglo XIX, atendiendo a los
7. Se encuentra en proceso de análisis por la arqueóloga. Victoria Isasmendi. 
contextos de asociación. Por otra parte, planteamos como hipótesis que los cordeles teñidos y sin teñir que se destacan por una coloración diferente en las piezas textiles conformaron una forma de hacer característica de los puneños y puneñas de mediados y fines del siglo XIX.

\section{Consideraciones finales}

A manera de reflexión destacamos la articulación de lo preexistente dado por los cordeles de fibra animal y lo nuevo que incorpora la población puneña, sean los lienzos de algodón o las telas industriales, vinculadas a un consumo moderno.

Para contextos republicanos proponemos entonces que la población puneña incorpora en la materialidad textil elementos de la realidad moderna y construye un espacio de autonomía, fortaleciendo lazos en la comunidad puesto que no se suprimen ni se reemplazan antiguos saberes prehispánicos, modos de hacer que conllevan una larga tradición en el lugar, como son la confección de cordeles de fibra vegetal y animal, con una tradición de milenios de antigüedad. Más bien se apropian de nuevas telas y se combinan en algunos casos para que resalte y se visibilice - de una manera destacadalo local con carácter ancestral, no sólo por la diferenciación de las fibras utilizadas para cada producto sino también por la contrastación de los colores.

A pesar de los numerosos cambios que se han producido con el devenir de los siglos - y el arribo de la modernidad- es posible afirmar que la tecnología textil es una de las prácticas actuales que más elementos de continuidad ha mantenido entre las comunidades andinas. En este continuum con transformaciones que conlleva la persistencia de la materialidad textil, propusimos en ella un espacio de negociación como una de las respuestas a la implementación de políticas de un nuevo orden social impuesto con la llegada del Estado moderno en el siglo XIX a Antofagasta de la Sierra. Esta práctica textil es, actualmente, una de las prácticas artesanales de mayor representatividad social, económica e identitaria en la sociedad puneña.

\section{Agradecimientos}

Este trabajo se llevó a cabo en el marco de los proyectos PIP-CONICET 464 y PIUNT 26/G404. Un especial agradecimiento a las familias Morales de Punta de la Peña y Peñas Coloradas, sin su generosa hospitalidad y calidez nada de esto sería posible. Unas gracias extendidas al equipo de investigación de Antofagasta de la Sierra, dirigido por el Lic. Carlos Aschero. Agradezco al arqueólogo Matias Lépori por ayudarme con la confección del abstract, a la arqueóloga Agustina Ponce por el tratamiento de las imágenes, a la Dra. Lorena Cohen y al Lic. Carlos Aschero por la lectura e interés con el que intercambiaron conmigo observaciones sobre este trabajo. Por último, gracias a los/as evaluadores/as y editores/as, con sus valiosos comentarios y sugerencias permitieron mejorar el manuscrito original. Aclaro que es de mi total responsabilidad lo aquí expuesto. 


\section{Deferencias citadas}

"Aláez García, A. (2001). Duelo Andino: sabiduría y elaboración de la muerte en los rituales mortuorios. Chungara. Revista de Arqueología Chilena, 33(2), 173-178.

"Arnold, D. Y. (1998). Hacia un Orden Andino de las Cosas. La Paz: Hisbol.

»Arnold, D. Y. (2000). “Convertirse en persona” El tejido: la terminología aymara de un cuerpo textil. En V. Solanilla Demestre (Ed.), Tejiendo sueños en el Cono Sur: Textiles Andinos: Pasado, Presente y Futuro (pp. 9-28). Barcelona: Grupos de Estudios Precolombinos (GEP), Departamento de Arte de la Universidad Autónoma de Barcelona.

》Arnold, D. y Espejo, E. (2013). El textil tridimensional. La naturaleza del textil como objeto y como sujeto. La Paz: Fundación Albo, Fundación Interamericana e Instituto de Lengua y Cultura Aymara.

» Aschero, C. A. (1999). El arte rupestre del desierto puneño y el noroeste argentino. En J. Berenguer y F. Gallardo (Eds.), Arte Rupestre en los Andes de Capricornio (pp. 97-135). Santiago de Chile, Chile: Museo Chileno de Arte Precolombino y Banco de Santiago.

" Aschero, C. A. (2007). Iconos, huancas y complejidad en la Puna Sur argentina. En A. E. Nielsen, M. C. Rivolta, V. Seldes, M. M. Vázquez y P. H. Mercolli (Eds), Producción y circulación prehispánicas de bienes en el sur andino (pp. 135-167). Córdoba: Brujas.

"Aschero, C. A. y Hocsman, S. (2011). Arqueología de las ocupaciones cazadorasrecolectoras de fines del Holoceno Medio de Antofagasta de la Sierra (Puna Meridional Argentina). Chungará. Revista de Arqueología Chilena, 43(ESPECIAL), 393-411.

» Aschero, C. A., Aguirre, G., Babot M. P., Bobillo, F., Cohen, M. L., Erramouspe, V., González Baroni, L. G., Hocsman, S., López Campeny, S. M. L., Marcos, M. S., Martel, A., Martinez, M. S. y Urquiza, S. V. (2016). Proyecto Arqueológico de las sociedades puneñas en la cuenca del río Punilla y áreas aledañas, Antofagasta de la Sierra, Catamarca. Informe a la Dirección Provincial de Antropología (DPA) de Catamarca. Manuscrito inédito.

" Babot, M.P. (2006). El papel de la molienda en la transición hacia la producción agropastoril: un análisis desde la Puna Meridional argentina. Estudios Atacameños, 32, 75-92.

" Babot, M. P., Aschero, C. A., Hocsman, S., Haros, M. C., González Baroni, L. y Urquiza, S. (2006). Ocupaciones agropastoriles en los sectores intermedios de Antofagasta de la Sierra (Catamarca): un análisis desde Punta de la Peña 9.1. Comechingonia, 9, 57-75.

"Benedetti, A. (2002). Los efectos de la inclusión. Transformaciones territoriales y reorganización de la red de lugares poblados en las tierras altas de Jujuy durante el siglo XX. Trabajo presentado en el XIII World Congress of the International Economic History Association. Buenos Aires, Argentina.

" Benedetti, A. (2005). Un territorio andino para un país pampeano. Geografía histórica del territorio de los Andes 1900-1943. (Tesis Doctoral inédita), Universidad de Buenos Aires, Argentina.

" Benedetti, A. (2009). Los usos de la categoría región en el pensamiento geográfico argentino. Scripta Nova, 13(286), 6-8.

"Bertrand, A. (1885) Memoria sobre las cordilleras del desierto de Atacama y Regiones limítrofes. Santiago de Chile: Imprenta Nacional.

»Boccara, G. (2002). Colonización, Resistencia y Mestizaje en las Américas (Siglos XVI y XX). Quito: Abya. 
» Boccara G. (2012). ¿Qué es lo "etno" en etnohistoria? La vocación crítica de los estudios etnohistóricos y los nuevos objetos de lucha. Memoria Americana, 20(1), 35-81.

»Bourdieu, P. (1990). Sociología y cultura. México: Grijalbo.

» Bourdieu, P. (2011). Las estrategias de la reproducción social. Buenos Aires: Siglo Veintiuno.

"Briones C. (2005). Formaciones de alteridad: contextos globales, procesos nacionales y provinciales. En C. Briones (Ed.), Cartografias argentinas: políticas indígenas y formaciones provinciales de alteridad (pp. 9-40). Buenos Aires: Antropofagia.

" Buscaglia S. (2011). Contacto y colonialismo. Aportes para una discusión crítica en arqueología histórica. En S. Cornero e I. Dosztal (Eds.), Anuario de Arqueología. Primer Simposio Magistral de Arqueología Colonial (pp.57-76). Rosario: Universidad Nacional de Rosario.

" Cereceda, V. (1990). “A partir de los colores de un pájaro...”. Boletín del Museo Chileno de Arte Precolombino, 4, 57-104.

»Cerri, D. (1903). El territorio de los Andes (República Argentina). Reseña geográfica descriptiva. Buenos Aires: Universidad Nacional de Jujuy.

"Cohen, M. L. (2010). Prácticas sociales, estrategias de visibilidad y construcción de la cartografía social durante el lapso de ca 1000-500 años AP, en Antofagasta de la Sierra, Catamarca - Perspectivas desde el sitio Peñas Coloradas 3 cumbre. (Tesis Doctoral Inédita), Universidad de Buenos Aires, Argentina.

»Cohen, M. L. (2014). Miradas desde y hacia los lugares de poder. Antofagasta de la Sierra entre 1000 y 1500 años D.C. Arqueología, 20(1), 47-72.

"Cohen, M. L., y Martínez, M. S. (2012). Formas de Perdurar... Resguardando identidades. Interpretaciones en torno a prácticas religiosas en Antofagasta de la Sierra. En R. Sánchez Patzy, J. L. Cladera, M. Weinberg y P. Mercolli (Eds.), Jornadas de Estudios Andinos. Pensando la Multiplicidad y la Unidad en los Andes (pp. 151-152). Buenos Aires: Facultad de Filosofía y Letras, Universidad de Buenos Aires.

"Corcuera, R. (2006). Mujeres de seda y tierra. Buenos Aires: Editorial Argentina.

"De Certeau, M. (1984). The practice of everyday life. Berkeley: University of Califormia Press.

»Deslandres, Y. (1985). El traje, imagen del hombre. Barcelona: Tusquets.

» Emery, I. (1966). The primary structure of fabrics. The Textile Museum. Washington D.C.: University of Washington Press.

»Escola, P. (2002). Caza y pastoralismo: un reaseguro para la subsistencia. Relaciones de la Sociedad Argentina de Antropología, XVII, 233-246.

"Escolar, D. (2007). Los dones étnicos de la Nación. Identidades huarpes y modos de producción de soberanía en Argentina. Buenos Aires: Prometeo.

»Espinosa, F. y Grüzmacher, M. L. (2002). Manual de conservación preventiva de textiles. Santiago de Chile: Fundación Andes.

» Flores Ochoa, J. A. y Kobayashi, Y. (2000). Pastoreo altoandino. Realidad, sacralidad y posibilidades. La Paz: Plural Editores.

"García, S., y Rolandi, D. (2000). Relatos y ritual referidos a la Pachamama en Antofagasta de la Sierra, Puna Meridional Argentina. Relaciones de la Sociedad Argentina de Antropología, 25, 7-25.

" García, S. y Rolandi D. (2003). Antofagasta de la Sierra, Provincia de Catamarca. Su historia en los documentos y la tradición oral. En A. Benedetti (Ed.), Puna de Atacama. Sociedad, economía y frontera (pp. 137-198). Córdoba: Alción Editora. 
" Gisbert T., Arze, S. y Cajías M. (1987). Arte textil y Mundo Andino. La Paz: Gisbert y Cia.

» González, M. L. (2017). Maquinaria de punto: desarrollo y vigencia en el diseño actual. Kepes, 14(15), 33-68.

" González Baroni, L. G. (2013). Contextos funerarios y vida cotidiana en Antofagasta de la Sierra, Catamarca. Un enfoque desde la bioantropología, el emplazamiento y dinámica de los entierros (ca. 1500-1000 años AP). (Tesis de Licenciatura inédita), Universidad Nacional de Tucumán, Argentina.

»Gupta, A. y Ferguson, J. (2008). Más allá de la "cultura": espacio, identidad y las políticas de la diferencia. Antípoda. Revista de Antropología y Arqueología, 7, 233-256.

» Hollen, N., Saddler, J. y Langford, A. (2001). Introducción a los textiles. México D.F: Limusa Noriega.

" Hutson, S. R. (2002). Built space and bad subjects: Domination and resistance at Monte Albán, Oaxaca, Mexico. Journal of Social Archaeology, 2(1), 53-80.

》Ingold, T. (2007). Materials against materiality. Archaeological Dialogues, 14(1), 16-20.

"Instituto Nacional de Estadística y Censos - INDEC (2012). Censo nacional de población, hogares y viviendas 2010. Censo del Bicentenario. Resultados definitivos. Ciudad Autónoma de Buenos Aires: Instituto Nacional de Estadística y Censos.

" Iñiguez, L. y Alem, R. (1996). La función de los camélidos como medio de transporte e intercambio en la región andina de Bolivia. Revista Mundial de Zootecnia, 86, 12-21.

"Isla, A. (2005). Estado y Comunidad. Políticas de identidad. Nuevos Mundos Mundos Nuevos, https//nuevomundo.revue.org/index33.html (Acceso: 01 de octubre, 2009).

" Jones, S. (2005). Categorías históricas e a praxis da identidade: a interpretação da etnicidade na arqueología histórica. En P. P. Funari, C. E. Orser Jr. y S. Nunes de Oliveira Schiavetto (Eds.), Identidades, Discurso y Poder. Estudos da Arqueologuia Contemporánea (pp. 27-43). San Pablo: Annablume Editora

» Lecoq, P. y Fidel, S. (2003). Prendas Simbólicas de Camélidos y ritos agropastorales en el sur de Bolivia. Textos Antropológicos, 14(1), 7-54.

»López Campeny, S. M. L. (200o). Tecnología, iconografía y ritual funerario tres dimensiones de análisis de los textiles formativos del Sitio Punta de la Peña 9. (Antofagasta de la Sierra-Argentina). Estudios Atacameños, 20, 29-65.

»López Campeny, S. M. L. (2001). Actividades domésticas y organización del espacio intrasitio. El sitio Punta de la Peña 9. (Antofagasta de la Sierra, Prov. De Catamarca). (Tesis de Licenciatura inédita), Universidad Nacional de Tucumán, Argentina.

»López Campeny, S. M. L. (2002). La trama del desierto. Textiles tempranos de Antofagasta de la Sierra (Puna meridional Argentina). Trabajo presentado en Actas de la reunión anual del Comité Nacional de Conservación Textil, [CD ROM]. San Pedro de Atacama.

"López Campeny, S. M. L. (2006-2007). El poder de torcer, anudar y trenzar a través de los siglos. Textiles y ritual funerario en la Puna Meridional Argentina. Cuadernos del Instituto Nacional de Antropología y Pensamiento Latinoamericano, 21, 143-155.

»López Campeny, S. M. L. (2009). Asentamiento, Redes Sociales, Memoria e Identidad Primer milenio de la era Antofagasta de la Sierra, Catamarca. (Tesis Doctoral inédita), Universidad Nacional de La Plata, Argentina.

» López Campeny, S. M. L. (2014). The agency of textile technology in some archaeological ritual contexts of Northwest Argentina. Journal of Anthropology and Archaeology, 2, 39-75. 
» López Campeny, S. M. L. y Aschero, C. A. (2006). Uso, mantenimiento y reciclaje de textiles. Un contexto funerario del sitio Punta de la Peña 4 (Antofagasta de la Sierra-Catamarca). Trabajo presentado en la $1^{\circ}$ Jornadas sobre estudio y conservación de textiles "Recuperando nuestros textiles...ayer y hoy”. Tucumán, Argentina.

» López Campeny, S. M. L., Romano, A. S, Rodríguez, M. F., Martel, A. y Corbalán, M. (2014). De aquí y de allá: análisis integral de un contexto funerario. Vínculos e interacciones sociales entre Puna meridional y Tierras Bajas orientales. Intersecciones en Antropología, 15, 201-218.

» Martel, A. R. y Aschero, C. A. (2007). Pastores en acción: Imposición iconográfica vs. autonomía temática. En A. Nielsen, M. Clara Rivolta, V. Seldes, M. M. Vázquez y P. H. Mercolli (Eds.), Producción y circulación prehispánicas de bienes en el sur andino (pp. 329349). Córdoba: Brujas.

"Martel, A., Curletto, S. R. y Del Bel, E. (2012). Arte rupestre y espacios de memoria: las representaciones del sitio Confluencia (Antofagasta de la Sierra, Catamarca, Argentina). Revista Chilena de Antropología, 25, 121-162.

» Martínez, C. J. L, Gallardo, V. P. y Martínez, B. (2002). Construyendo identidades desde el poder: los indios en los discursos republicanos de inicios del Siglo XIX. En G. Boccara (Ed.), Colonización, resistencia y mestizaje en las Américas siglos XVI-XX (pp. 27-46). Quito: Abya-Yala.

" Martínez, J. G. (2014). Contributions to the knowledge of natural history and archaeology of hunter-gatherers of Antofagasta de la Sierra (Southern Argentinian Puna): the case of Peñas de las Trampas 1.1. En E. Pintar (Ed.), Hunter-gatherers from a high-altitude desert. People of the Salt Puna (northwest Argentina) (pp.1-23). Oxford: BAR International Series, Archaeopress.

» Martínez, J. G., Mondini, N. M., Pintar, E. y Reigadas, M. C. (2010). Cazadores-recolectores tempranos de la Puna Meridional Argentina: avances en su estudio en Antofagasta de la Sierra (Pleistoceno Final-Holoceno Temprano/Medio). En J. R. Bárcena y H. Chiavazza (Eds.), Arqueología Argentina en el Bicentenario de la Revolución de Mayo (pp. 1691-1696). Mendoza: Facultad de Filosofía y Letras Universidad Nacional de Cuyo, Instituto de Ciencias Humanas, Sociales y Ambientales - Consejo Nacional de Investigaciones Científicas y Técnicas.

» Martinez, M. S. (2012). Prácticas Textiles resignificadas en Contextos de Transformaciones en Antofagasta de la Sierra (Provincia de Catamarca-Argentina). Integrando materialidad del pasado y la oralidad del presente. (Tesis de Licenciatura inédita), Universidad Nacional de Tucumán, Argentina.

" Martinez, M. S. (2013). Materialidades que disparan memorias...textiles del pasado y tejedoras de Antofagasta de la Sierra, Provincia de Catamarca. En J. Bárcena y S. Martín (Eds.), Arqueología Argentina en el Bicentenario de la Asamblea General Constituyente de 1813 (p. 151). La Rioja, Argentina: Instituto de Ciencias Humanas, Sociales y Ambientales - Consejo Nacional de Investigaciones Científicas y Técnicas.

» Martinez, M. S. (2017). Tecnología textil histórica en contextos rituales prehispánicos. Antofagasta de la Sierra, Catamarca-Noroeste Argentino. Comechingonia, 21(2), 351-378.

» Méndez, P. (2009). Herencia textil, identidad indígena y recursos económicos en la Patagonia Argentina. Estudio de un caso: la comarca de la meseta central de la pcia. de Chubut. Revista de Antropología Americana, 4(1), pp. 11-53.

» Miller, D. (2005). Materiality. Durham: Duke University Press.

» Munsell Color (1977). Munsell Color Charts for Plant Tissues. New York: Munsell Color.

» Munsell Color (2009). Munsell Soil-Color Charts. Michigan: Munsell Color. 
" Murra, J. (1975). Formaciones Económicas y Políticas del Mundo Andino. Lima: Instituto de Estudios Peruanos.

»Palomeque, S. (1989). La circulación mercantil en las provincias del interior, 1800-1810. Anuario Instituto de Estudios Históricos Sociales, 4, 131-210.

»Quiroga, L. (2015). Del páramo a la puna. Textos y contextos arqueológicos para una descripción del paisaje altoandino en la Gobernación del Tucumán. CORPUS. Archivos virtuales de la alteridad americana, 5(2), https://journals.openedition.org/ corpusarchivos/1516. (Acceso: 30 de septiembre, 2016).

"Rodríguez, M. F. (2005). Human evidence from the mid-Holocene in the Salty Argentine Puna. Analysis of the archaeobotanical record. Quaternary International, 132(1), 15-22.

"Rodríguez, M. F. (2008). Recursos vegetales y tecnofacturas en un sitio arqueológico de la Puna Meridional Argentina, Área Centro-Sur Andina. Darwiniana, 46(2), 240-257.

》 Rolandi de Perrot, D. y Jiménez de Pupareli, D. (1983-1985). La tejeduría tradicional de la Puna Argentino-Boliviana. Cuadernos del Instituto Nacional de Antropología, 1, 205-289.

》 Ruiz Espinosa, C. P. (2013). Guía Técnica sobre la Elaboración de Tejidos de Punto en Máquinas Rectilíneas. (Tesis de Licenciatura inédita), Universidad Técnica del Norte, Ecuador.

"Salerno, M. (2006). Arqueología de la indumentaria. Prácticas e identidad en los Confines del Mundo Moderno (Antártida, Siglo XIX). Buenos Aires: Del Tridente.

» Scott, J. (1990) Los dominados y el arte de la Resistencia. Discursos ocultos. México D.F.: Colección Nueva Era.

"Sillar. B. (2009). The social agency of things? Animism and Materiality in the Andes. Cambridge Archaeological Journal, 19(3), 367-377.

"Silliman, S. (2001). Agency, practical politics and the archaeology of culture contact. Journal of social archaeology, 1(2), 190-209.

"Silliman, S. (2009). Change and continuity, practice and memory: native american persistence in colonial New England. American Antiquity, 74(2), 211-230.

» Teves, L. S. (2011). El estudio etnográfico de la actividad textil como aporte a la caracterización del modo de vida en el pueblo de Molinos y zona de influencia (provincia de Salta). (Tesis Doctoral inédita), Universidad Nacional de la Plata, Argentina.

» Turneau, I. (1993). Tejidos de Punto. En M. Ginsbur (Ed.), Historia de los Textiles (pp. 147159). Madrid: Libsa.

"Urquiza, S. V., Romano, A. S. y López Campeny, S. M. L. (2013). Historia ocupacional y prácticas sociales: Un análisis arqueofaunístico contextual. Sitio Piedra Horadada 2, Antofagasta de la Sierra, Catamarca, Argentina. En A. Izeta, y G. Mengoni Goñalons (Eds.), De la Puna a las Sierras: Avances y Perspectivas en Zooarqueología Andina (pp. 121144). Oxford: BAR International Series 2564.

"Urquiza, S. y Aschero, C. (2014). Economía animal a lo largo del Holoceno en la Puna Austral Argentina: Alero Punta de la Peña 4. Cuadernos del Instituto Nacional de Antropología y Pensamiento Latinoamericano - Series Especiales, 2(1), 86-112.

»Van Kessel, J. (2001). El ritual Mortuorio de los Aymara de Tarapacá como vivencia y crianza de la vida. Chungara. Revista de Arqueología Chilena, 33(2), 221-234.

"Voss, B. L. (2008). Ethnogenesis and Archaeology of identity. The Archaeology of Ethnogenesis. Race and sexuality in Colonial San Francisco. Berkeley y Los Angeles: University of California Press.

»Williams, R. (1993). La Revolución Industrial; 1780-1880. En M. Ginsburg (Ed.), La historia de los textiles (pp. 55-71). Madrid: Libsa. 